\title{
New Insights Into the Polar Lipid Composition of Extremely Halo(alkali)philic Euryarchaea From Hypersaline Lakes
}

\author{
Nicole J. Bale ${ }^{1 *}$, Dimitry Y. Sorokin ${ }^{2,3}$, Ellen C. Hopmans ${ }^{1}$, Michel Koenen ${ }^{1}$, \\ W. Irene C. Rijpstra ${ }^{1}$, Laura Villanueva ${ }^{1}$, Hans Wienk ${ }^{4}$ and Jaap S. Sinninghe Damsté ${ }^{1,5}$ \\ ${ }^{1}$ Department of Marine Microbiology and Biogeochemistry, NIOZ Royal Institute for Sea Research, Utrecht University, Texel, \\ Netherlands, ${ }^{2}$ Research Centre of Biotechnology, Winogradsky Institute of Microbiology, Russian Academy of Sciences, \\ Moscow, Russia, ${ }^{3}$ Department of Biotechnology, Faculty of Applied Sciences, Delft University of Technology, Delft, \\ Netherlands, ${ }^{4}$ NMR Spectroscopy, Bijvoet Center for Biomolecular Research, Utrecht University, Utrecht, Netherlands, \\ ${ }^{5}$ Department of Earth Sciences, Faculty of Geosciences, Utrecht University, Utrecht, Netherlands
}

We analyzed the polar membrane lipids of 13 strains of halo(alkali)philic euryarchaea from hypersaline lakes. Nine belong to the class Halobacteria, representing two functional groups: aerobic polysaccharide utilizers and sulfur-respiring anaerobes. The other four strains represent halo(alkali)philic methanogens from the class Methanomicrobia and a recently discovered class Methanonatronarchaeia. A wide range of polar lipids were detected across the 13 strains including dialkyl glycerol diethers (archaeols), membrane-spanning glycerol tetraethers and diether-based cardiolipins. The archaeols contained a range of core lipid structures, including combinations of $\mathrm{C}_{20}$ and $\mathrm{C}_{25}$ isoprenoidal alkyl chains, unsaturations, and hydroxy moieties. Several diether lipids were novel, including: (a) a phosphatidylglycerolhexose (PG-Gly) headgroup, (b) a N,N,N-trimethyl aminopentanetetrol (APT)-like lipid with a methoxy group in place of a hydroxy group on the pentanetetrol, (c) a series of polar lipids with a headgroup with elemental composition of either $\mathrm{C}_{12} \mathrm{H}_{25} \mathrm{NO}_{13} \mathrm{~S}$ or $\mathrm{C}_{12} \mathrm{H}_{25} \mathrm{NO}_{16} \mathrm{~S}_{2}$, and (d) novel cardiolipins containing a putative phosphatidylglycerolphosphate glycerophosphate (PGPGP) polar moiety. We found that the lipid distribution of the 13 strains could be generally separated into two groups, the methanogens (group) and the Halobacteria (class) based on the presence of specific core lipids. Within the methanogens, adaption to a high or more moderate salt concentration resulted in different ratios of glycerol dialkyl glycerol tetraethers (GDGTs) to archaeol. The methanogen Methanosalsum natronophilum $\mathrm{AME}^{\top}{ }^{\top}$ had the most complex diether lipid composition of any of the 13 strains, including hydroxy archaeol and macrocyclic archaeol which we surmise is an order-specific membrane adaption. The zwitterionic headgroups APT and APT-Me were detected only in the Methanomicrobiales member Methanocalculus alkaliphilus $\mathrm{AMF}^{\top}$ which also contained the highest level of unsaturated lipids. Only alkaliphilic members of the Natrialbales order contained PGPGP cardiolipins and the PG-Gly headgroup. The four analyzed neutrophilic members of the Halobacteria were characterized by the presence of sulfur-containing headgroups and glycolipids. The presence of cardiolipins with one or more $\mathrm{i}-\mathrm{C}_{25}$ alkyl chains, generally 
termed extended archaeol (EXT-AR), in one of the Methanonatronarchaeia strains was unexpected as only one other order of methanogenic archaea has been reported to produce EXT-AR. We examined this further by looking into the genomic potential of various archaea to produce EXT-AR.

Keywords: halo(alkali)philic, euryarchaea, haloarchaea, glycerol tetraether, membrane spanning lipids, cardiolipin, polar lipid, archaeol

\section{INTRODUCTION}

Extremely halophilic euryarchaea from the class Halobacteria, commonly referred to as haloarchaea, have attracted attention both as an object of fundamental research in extremophiles and as producers of extremophilic enzymes with biotechnological potential (Oren, 2002; Begemann et al., 2011; Andrei et al., 2012; Amoozegar et al., 2017). Recently, the knowledge of such euryarchaea has significantly increased by the discovery of anaerobic respiration, the ability to use chitin and cellulose as growth substrates and by the inclusion of relatives outside of the class Halobacteria such as methanogens (Sorokin et al., 2015b,c, 2016a,b, 2017a,b, 2018a, 2019). The recent discovery of extremely halo(alkali)philic methanogenic euryarchaea of the class Methanonatronarchaeia in hypersaline lakes has provided particular insights into the origin of methanogenesis and the strategies methanogens employ to thrive under hypersaline conditions (Sorokin et al., 2017a). A wide range of haloarchaea has been found to exist in hypersaline $\mathrm{NaCl}-\mathrm{Na}_{2} \mathrm{SO}_{4}$-based lakes with neutral $\mathrm{pH}$ and alkaline soda lakes with a previously unrecognized potential to utilize native insoluble celluloses and chitin as their sole growth substrate (Sorokin et al., 2015c, 2018a, 2019) and the capability of sulfur respiration in salt-saturated media (Sorokin et al., 2016a,b, 2017b, 2018c).

Sustaining optimal membrane function is crucial for all microorganisms in order to maintain cell homeostasis, but is a particular challenge in extreme environments such as hypersaline lakes. The characteristic membrane lipids of haloarchaea form the barrier between the cell's internal functions and the harsh outside environment. In general, the membrane lipids of Archaea are characterized by the presence of ether linkages between a glycerol moiety and isoprene-based alkyl chains. Archaeal membrane lipids include sn-2,3-diphytanyl glycerol diether with two $\mathrm{C}_{20}$ isoprenoid chains (archaeol, AR), extended archaeol (EXT-AR, with a $\mathrm{C}_{20}$ and $\mathrm{C}_{25}$ isoprenoid chain) and tetraethers with two glycerol moieties connected by two $\mathrm{C}_{40}$ isoprenoid chains [glycerol dialkyl glycerol tetraethers (GDGT)]. Membrane-spanning GDGTs can contain up to eight cyclopentane moieties (i.e., GDGT-n, where $n$ is the number of cyclopentane moieties). Membrane-spanning GDGTs have not been detected in members of the class Halobacteria. Archaea also produce bisphosphatidylglycerol diethers, analogous to the diacyl cardiolipins found in Bacteria and Eukarya (Corcelli et al., 2000; Lattanzio et al., 2002; Corcelli, 2009; Angelini et al., 2012; Yoshinaga et al., 2012). The membrane polar lipids of halophilic archaea, mostly from the class Halobacteria, have been characterized in a wide range of studies (Kushwaha et al., 1975; Kates et al., 1993; de Souza et al., 2009; Angelini et al., 2012; Dawson et al., 2012; Lobasso et al., 2015). Phosphatidylglycerophosphate methyl ester (PGP-Me) has often found to be the dominant polar headgroup. It is thought that the bulky, double charged nature of this headgroup contributes to membrane stability at high salt concentrations (Tenchov et al., 2006). Indeed, Kellermann et al. (2016) observed that for the neutrophilic haloarchaeon Haloferax (H.) volcanii, there was a correlation between the amount of PGP-Me and the concentration of $\mathrm{Mg}^{2+}$ in the media during culturing experiments. Kellermann et al. (2016) hypothesized that the terminal methyl group of PGP-Me acts as an antenna, while the closely positioned, negatively charged neighboring phosphate moieties allow PGP-Me to bind divalent cations [as opposed to monovalent cation bonding to phosphatidylglycerol (PG) or cardiolipins, cf. Figure 9 of Kellermann et al. (2016)]. They suggested that by up- or downregulating the number of negative charges at its surface, a cell can balance membrane permeability under varying salt concentrations. Indeed, the most important membrane adaption for haloarchaea is low permeability to water, protons and monovalent cations (i.e., $\mathrm{Na}^{+}$and $\mathrm{K}^{+}$) (Oger and Cario, 2013). Other phospho-based polar headgroups have been detected in haloarchaea in lesser proportions along with some glyco- and sulfo-lipids (Kates, 1992; Koga and Morii, 2005). Diether lipids are advantageous in extreme environments such as hypersaline conditions, and are considered to be a critical part of the "salt-in" strategy generally employed by haloarchaea to cope with extreme salinity, by which they accumulate a high intracellular concentration of $\mathrm{KCl}$, while excluding $\mathrm{Na}^{+}$(Oren, 1999). In particular, the presence of unsaturated AR and EXT-AR are characteristic of haloarchaea (Dawson et al., 2012; Oger and Cario, 2013). Indeed, Kellermann et al. (2016) observed for $H$. volcanii an increase in the degree of unsaturation with increasing $\mathrm{Na}^{+}$levels particularly within AR with a PG headgroup (PG-AR). However, Kellermann et al. (2016) noted that the total pool of $\mathrm{AR}$ in $H$. volcanii did not exhibit the same trend in unsaturation, which they suggested was due to impaired growth performance at both the low $\left(1 \mathrm{M} \mathrm{Na}^{+}\right)$and high $\left(5 \mathrm{M} \mathrm{Na}^{+}\right)$ends of the salt concentration range. While lipid analysis is an essential tool for understanding archaeal membrane composition, culturing conditions are known to affect this composition (Elling et al., 2015; Kellermann et al., 2016) and thus it is also useful to examine lipid synthesis genes (e.g., Villanueva et al., 2014) to determine not only the present but also the dormant lipid species within an organism's inventory.

In this study the polar lipid composition of 13 strains of halo(alkali)philic euryarchaea (Table 1; Figure 1) isolated 
from different hypersaline lakes was analyzed using High Performance Liquid Chromatography-Mass Spectrometry (HPLC-MS) and Nuclear Magnetic Resonance (NMR) spectroscopy. Among them are four methanogenic species, of which two (Methanonatronarchaeum (Mn.) thermophilum $\mathrm{AMET}^{\mathrm{T}}$ and "Candidatus (Ca.) Methanohalarchaeum (Mh.) thermophilum" HMET1) are extremely halophilic methylreducers forming a novel class Methanonatronarchaeia (Sorokin et al., 2017a, 2018b), while the other two (Methanosalsum (Ms.) natronophilum $\mathrm{AME}^{\mathrm{T}}$ and Methanocalculus (Mc.) alkaliphilus $\mathrm{AMF}^{\mathrm{T}}$ ) are haloalkaliphiles from soda lakes (Sorokin et al., 2015b). Haloalkaliphiles from soda lakes are not strictly halophilic and their name is applied to discriminate them from freshwater alkaliphiles. Mc. alkaliphilus $\mathrm{AMF}^{\mathrm{T}}$ can be regarded as a moderately salt-tolerant alkaliphile (growth up to $2 \mathrm{M}$ total $\mathrm{Na}^{+}$), while $M$ s. natronophilum $\mathrm{AME}^{\mathrm{T}}$ is an extremely salt-tolerant alkaliphile (growth up to $4 \mathrm{M}$ total $\mathrm{Na}^{+}$). Five haloarchaeal isolates are aerobic polysaccharide utilizers: cellulolytic "Halococcoides (Hc.) cellulosivorans" HArcel1 ${ }^{\mathrm{T}}$, Natronobiforma (Nb.) cellulositropha AArcel5 and uncharacterised strain AArcel7 and two natronarchaeal chitinolytic strains "Natrarchaeobius (Na.) chitinivorans" $\mathrm{AArch} 44^{\mathrm{T}}$ and "Na. haloalkaliphilus" AArcht-S1 ${ }^{\mathrm{T}}$ are members of the orders Halobacteriales and Natrialbales in the class Halobacteria. The last four strains belong to a group of anaerobic sulfur-respiring haloarchaea. Two halophilic strains comprise two novel genera in the family Halobacteriaceae: Halanaeroarchaeum (Hn.) sulfurireducens $\mathrm{HSR} 2^{\mathrm{T}}$, which grows exclusively by acetate-dependent sulfur respiration (Sorokin et al., 2016a,b), and Halodesulfurarchaeum (Hd.) formicicum HSR6 $^{\mathrm{T}}$, which is capable of utilizing either formate or hydrogen as their electron donor, and elemental sulfur, thiosulfate or dimethylsulfoxide as electron acceptors (Sorokin et al., 2017b). The two other strains, AArc-Mg and AArc-S1, are alkaliphilic haloarchaea, capable of growth by dissimilatory sulfur reduction [provisionally belonging to a new species "Natronolimnobius (Nl.) sulfurireducens" (Natrialbales) and a new genus and species "Halalkaliarchaeum (Ha.) desulfuricum" (Haloferacales) (Sorokin et al., 2018c)]. While the dominant lipid groups have been previously reported for a number of these strains, our work reports the full range of dialkyl glycerol diether and tetraether membrane lipids present in the 13 strains, including the in-depth structural characterization of novel compounds.

\section{MATERIALS AND METHODS}

\section{Culturing}

Mc. alkaliphilus $\mathrm{AMF}^{\mathrm{T}}$ was grown at $0.6 \mathrm{M}$ total $\mathrm{Na}^{+}$and $30^{\circ} \mathrm{C}$ with formate as electron donor and acetate as carbon source and Ms. natronophilum $\mathrm{AME}^{\mathrm{T}}$ at $2 \mathrm{M}$ total $\mathrm{Na}^{+}$with methanol as a sole substrate, both at $\mathrm{pH}$ 9.5, as described previously (Sorokin et al., 2015a,b). The other 11 extremely halophilic archaeal isolates were grown at $4 \mathrm{M}^{\text {total }} \mathrm{Na}^{+}, 5 \mathrm{mM} \mathrm{KCl}$ and $1 \mathrm{mM} \mathrm{Mg}^{2+}$ until late exponential growth phase. Mn. thermophilum AMET1 ${ }^{\mathrm{T}}$ and "Ca. Mh. thermophilum" HMET1 were grown anaerobically with methanol and formate $(50 \mathrm{mM}$ each) and yeast extract as carbon source $\left(100 \mathrm{mg} \mathrm{L}^{-1}\right)$ at $50^{\circ} \mathrm{C}$ and $\mathrm{pH}$ either $9.5(2 \mathrm{M}$
$\mathrm{Na}^{+}$as carbonates and $\left.2 \mathrm{M} \mathrm{NaCl}\right)$ or $7.0(4 \mathrm{M} \mathrm{NaCl})$, respectively (Sorokin et al., 2018b). Sulfur-reducing neutrophilic haloarchaea were grown anaerobically with sulfur as the electron acceptor and either $10 \mathrm{mM}$ pyruvate (Hn. sulfurireducens $\mathrm{HSR} 2^{\mathrm{T}}$ ) or $50 \mathrm{mM}$ formate $\left(\mathrm{Hd}\right.$. formicicum HSR6 ${ }^{\mathrm{T}}$ ) as the electron donor and $200 \mathrm{mg} \mathrm{L}^{-1}$ of yeast extract as carbon source at $37^{\circ} \mathrm{C}$ as described by Sorokin et al. (2016a,b, 2017b). Alkaliphilic sulfur reducing haloarchaea were cultivated anaerobically with sulfur as electron acceptor at $37^{\circ} \mathrm{C}$ with $10 \mathrm{mM}$ butyrate as the electron donor at $\mathrm{pH} 9.8$ (strain AArc-Mg) or with $20 \mathrm{mM}$ pyruvate at $\mathrm{pH} 9.2$ (strain $\mathrm{AArc}^{-\mathrm{Sl}^{\mathrm{T}}}{ }^{\text {) }}$ (Sorokin et al., 2018c). Aerobic alkaliphilic polysaccharide utilizers were grown either with $10 \mathrm{mM}$ cellobiose at $\mathrm{pH} 9.5$ (strains AArcel5 $5^{\mathrm{T}}$ and AArcel7) or $10 \mathrm{mM} \mathrm{N}$-acetylglucosamine (strains AArcht $4^{\mathrm{T}}$ and AArcht$\mathrm{Sl}^{\mathrm{T}}$ ) at $\mathrm{pH} 9.5$ and 9.1, respectively, as described previously (Sorokin et al., 2015c, 2018a, 2019). All cultures were grown in duplicate and the final biomass was pooled together in a single sample for lipid analysis.

\section{Hydrolysis of Biomass and Core Lipid Analysis}

In order to remove the headgroups from the intact polar lipids (IPLs) and to obtain the remaining core lipids the freeze-dried biomass was hydrolyzed with $\mathrm{HCl} / \mathrm{MeOH}(1.5 \mathrm{~N})$ by refluxing for $3 \mathrm{~h}$. The hydrolysate was adjusted with aqueous $\mathrm{KOH}$ to $\mathrm{pH} 5$, extracted three times with dichloromethane, and dried over $\mathrm{Na}_{2} \mathrm{SO}_{4}$.

\section{HPLC-MS Analysis of GDGTs and AR}

The hydrolyzed biomass extracts were redissolved in hexane:isopropanol (99:1, v:v) and filtered through a $0.45 \mu \mathrm{m}$ PTFE filter and analyzed using HPLC-atmospheric pressure chemical ionization/mass spectrometry (HPLC-APCI/MS) on an Agilent 1100/Hewlett Packard 1100 MSD instrument equipped with automatic injector and HP-Chemstation software according to Hopmans et al. (2000) with the following modifications. Separation was achieved in normal phase with two Prevail Cyano columns in series $(150 \times 2.1 \mathrm{~mm} ; 3 \mu \mathrm{m})$ with a starting eluent of hexane:propanol (99.5:0.5, v:v) and a flow rate of $0.2 \mathrm{~mL}$ $\mathrm{min}^{-1}$. This remained isocratic for $5 \mathrm{~min}$ followed by a linear gradient to $1.8 \%$ propanol at $45 \mathrm{~min}$. The injection volume was $10 \mu \mathrm{L}$. An external standard of AR:GDGT-0 (1:1, w:w) run in sequence before and after the samples was used to quantify AR and GDGT-0. GDGT-1 was assumed to have the same response as GDGT-0 and was in this way semi-quantified. Hereafter, the concentrations of AR and GDGTs are expressed as percent of their total combined concentration.

\section{GC-MS Analysis of Mono and Diethers}

Hydrolyzed biomass extracts were methylated with diazomethane in diethyl ether which was removed under a stream of $\mathrm{N}_{2}$ and trimethylsilylated using N,Obis(trimethylsilyl)trifluoroacetamide (BSTFA) and pyridine (1:1; $20 \mathrm{~min}$ at $60^{\circ} \mathrm{C}$ ). Gas chromatography (GC) was performed using a Hewlett Packard 6890 gas chromatograph equipped with an on-column injector and a flame ionization detector (FID). A fused silica capillary column (CP Sil5 $25 \times 0.32 \mathrm{~mm}, d f=$ 


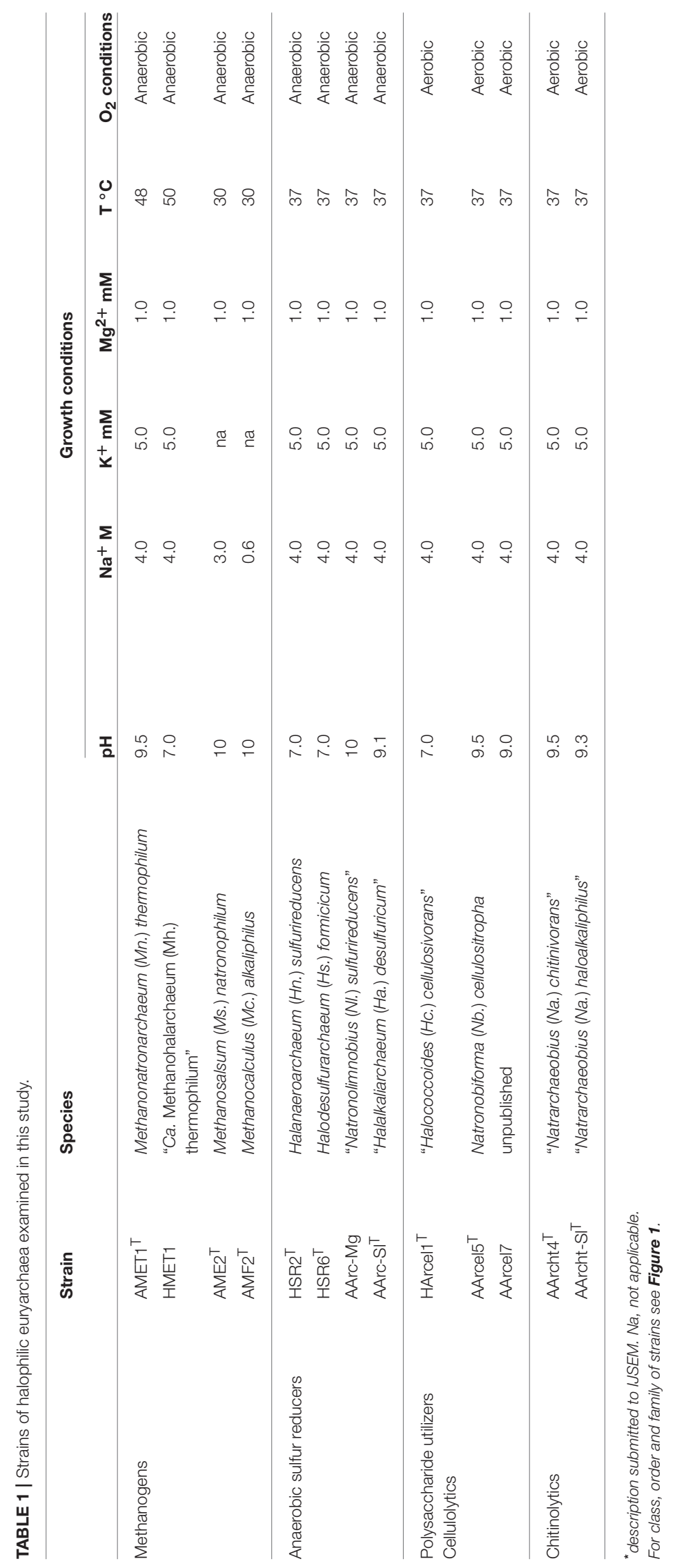




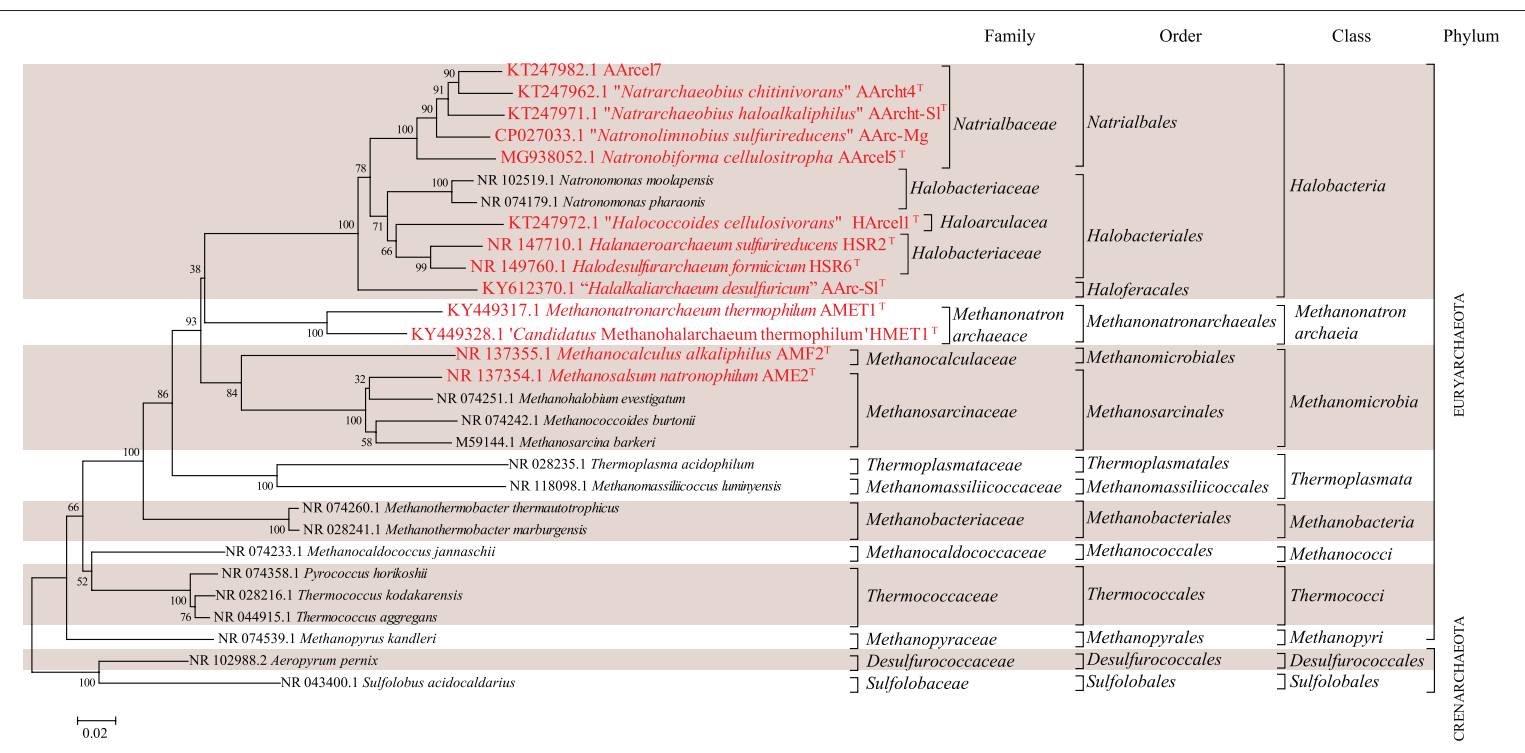

FIGURE 1 | 16S-rRNA-based phylogenetic tree showing position of the investigated halo(alkali)philic strains amongst other archaeal lineages. Bootstrap test values $(1,000$ replicates) are shown next to the branches. Bar scale indicates number of base substitutions per site. Colored boxes are a visual aid.

$0.12 \mu \mathrm{m}$ ) with helium as a carrier gas was used. The samples were injected at $70^{\circ} \mathrm{C}$. The GC oven temperature was subsequently raised to $130^{\circ} \mathrm{C}$ at a rate of $20^{\circ} \mathrm{C} \mathrm{min}-1$, and to $320^{\circ} \mathrm{C}$ at $4^{\circ} \mathrm{C}$ $\mathrm{min}^{-1}$. The temperature was then held constant for $15 \mathrm{~min}$. Additionally, all hydrolyzed fractions were analyzed by GC-MS for compound identification. The structural designation of lipids was evaluated by the comparison of their retention times and mass spectral fragmentation patterns with standards and with published spectra (e.g. Pancost et al., 2001). GC-MS was conducted using Thermo Finnigan Trace Ultra GC connected to ThermoFinnigan DSQ MS operated at $70 \mathrm{eV}$, with a mass range $\mathrm{m} / \mathrm{z} 50-800$ and 3 scans s$^{-1}$ with a silica column (CP Sil-5, 25 $\times 0.32 \mathrm{~mm}$ ) and $\mathrm{He}$ as the carrier gas at a constant flow rate of $2 \mathrm{~mL} \mathrm{~min}{ }^{-1}$. The oven temperature program initiated at $70^{\circ} \mathrm{C}$, increased first at a rate of $20^{\circ} \mathrm{C} \mathrm{min}^{-1}$ to $130^{\circ} \mathrm{C}$, and next at a rate of $4^{\circ} \mathrm{C} \mathrm{min}^{-1}$ to the final temperature of $320^{\circ} \mathrm{C}$, which was held for $10 \mathrm{~min}$.

GC peak area response (FID) of the mono and diethers was recorded. One of the diethers, AR, had previously been quantified (by HPLC-MS, section HPLC-MS analysis of GDGTs and AR). The two separate hydrolysis-derived ether lipid data sets (GC-MS derived and HPLC-MS derived), were both normalized to AR and combined to give an estimate of the total ether distribution (in percent of the total, Table 2). Combining the data sets involved several assumptions, such as that AR had been conserved equally during the two analyses and that the response of the ethers during GC-MS analysis was uniform. Hence this combined data set should be examined with these caveats in mind.

\section{IPL Extraction and Analysis}

Lipids were extracted from freeze-dried biomass using a modified Bligh-Dyer procedure (Schouten et al., 2008). Briefly, the biomass was treated ultrasonically three times for $10 \mathrm{~min}$ with a solvent mixture of methanol, dichloromethane and phosphate buffer $(2: 1: 0.8, v: v: v)$. After sonication, the combined supernatants were phase-separated by adding additional dichloromethane and buffer to a final solvent ratio of 1:1:0.9 (v:v:v). The organic phase containing the IPLs was collected and the aqueous phase re-extracted two times with dichloromethane. Finally, the combined extract was dried under a stream of $\mathrm{N}_{2}$ gas. Before analysis, the extract was redissolved in a mixture of $n$-hexane:2propanol:water (72:27:1, v:v:v) at a concentration of $2 \mathrm{mg} \mathrm{mL}^{-1}$ and aliquots were filtered through $0.45 \mu \mathrm{m}$ regenerated cellulose syringe filters ( $4 \mathrm{~mm}$ diameter; Grace Alltech, Deerfield, IL).

\section{HPLC-ITMS}

For general IPL screening, the IPL extracts were analyzed by high performance liquid chromatography-ion trap mass spectrometry (HPLC-ITMS) according to Sturt et al. (2004) with modifications as described previously (Sinninghe Damsté et al., 2011). The analysis was performed on an Agilent 1,200 series HPLC (Agilent, San Jose, CA), equipped with thermostatted auto-injector and column oven, coupled to an LTQ XL linear ion trap with Ion Max source with electrospray ionization (ESI) probe (Thermo Scientific, Waltham, MA). Separation was achieved on a LiChrospher diol column $(250 \times 2.1 \mathrm{~mm}$, $5 \mu \mathrm{m}$ particles; Alltech) maintained at $30^{\circ} \mathrm{C}$. The following elution program was used with a flow rate of $0.2 \mathrm{~mL} \mathrm{~min}^{-1}$ : $100 \%$ A for $1 \mathrm{~min}$, followed by a linear gradient to $66 \%$ A: $34 \% \mathrm{~B}$ in $17 \mathrm{~min}$, maintained for $12 \mathrm{~min}$, followed by a linear gradient to $35 \% \mathrm{~A}: 65 \% \mathrm{~B}$ in $15 \mathrm{~min}$, where $\mathrm{A}=$ hexane/2-propanol/formic acid/14.8 $\mathrm{M} \mathrm{NH}_{3 a q}$ (79:20:0.12:0.04, $\mathrm{v}: \mathrm{v}: \mathrm{v}: \mathrm{v})$ and $\mathrm{B}=2$-propanol/water/formic acid/ $14.8 \mathrm{M} \mathrm{NH}_{3 \mathrm{aq}}$ (88:10:0.12:0.04, v:v:v:v). The lipid extract was analyzed by an MS routine where a positive ion $\operatorname{scan}(m / z 400-2,000)$ was followed by a data dependent $\mathrm{MS}^{2}$ experiment where the base 


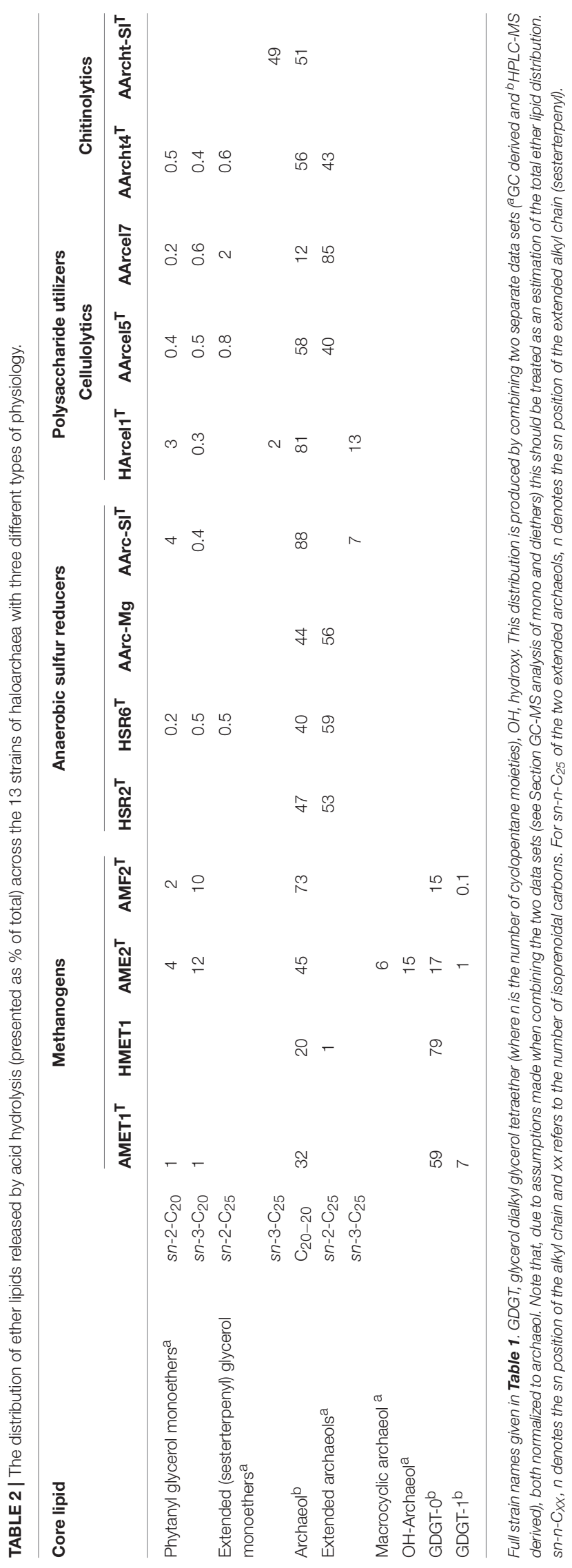

peak of the mass spectrum was fragmented (normalized collision energy (NCE) 25, isolation width 5.0, activation Q 0.175). This was followed by a data-dependent $\mathrm{MS}^{3}$ experiment where the base peak of the $\mathrm{MS}^{2}$ spectrum was fragmented under identical fragmentation conditions. This process was repeated on the second to fourth most abundant ions of the initial mass spectrum. Identification of the IPLs was carried out by comparison of their masses and their diagnostic fragmentations in $\mathrm{MS}^{2}$ with those described in the literature (e.g., Ferrante et al., 1987; Kates et al., 1993; Yoshinaga et al., 2011).

Intact polar lipids (IPLs) were quantified in terms of their MS peak area response. As different IPLs show different response behavior, the relative abundance of peak area does not necessarily reflect the actual relative abundance of the different IPLs. However, this method allows for comparison between the strains analyzed in this study, especially as they all contained at least one, but generally three, lipid groups in common. The peak areas were determined from extracted ion chromatograms of the combined $[\mathrm{M}+\mathrm{H}]^{+},\left[\mathrm{M}+\mathrm{NH}_{4}\right]^{+}$, and $[\mathrm{M}+\mathrm{Na}]^{+}$ion (where present) for each individual IPL species. The peak areas for the individual species were summed for data handling in groups based on headgroups and/or core lipids.

\section{UHPLC-HRMS}

Additional analysis of selected extracts was carried out using an ultra-high performance liquid chromatography-high resolution mass spectrometry (UHPLC-HRMS) method (Besseling et al., 2018) in order to determine the accurate mass of certain unknown compounds. An Agilent 1290 Infinity I UHPLC equipped with thermostatted auto-injector and column oven, coupled to a Q Exactive Orbitrap MS with Ion Max source with heated electrospray ionization (HESI) probe (Thermo Fisher Scientific, Waltham, MA) was used. Separation was achieved on an YMC-Triart Diol-HILIC column $(250 \times 2.0 \mathrm{~mm}$, $1.9 \mu \mathrm{m}$ particles, pore size $12 \mathrm{~nm}$; YMC Co., Ltd, Kyoto, Japan) maintained at $30^{\circ} \mathrm{C}$. The eluent composition and flow rate were the same as described above for the Agilent 1200/LTQ $\mathrm{XL}$ ion trap HPLC-MS system although the elution program was adjusted thus: $100 \% \mathrm{~A}$, followed by a linear increase to $30 \% \mathrm{~B}$ at $20 \mathrm{~min}$, followed by a $15 \mathrm{~min}$ hold, and a further increase to $60 \% \mathrm{~B}$ at $50 \mathrm{~min}$. Positive ion ESI settings were: capillary temperature, $275^{\circ} \mathrm{C}$; sheath gas $\left(\mathrm{N}_{2}\right)$ pressure, 35 arbitrary units (AU); auxiliary gas $\left(\mathrm{N}_{2}\right)$ pressure, $10 \mathrm{AU}$; spray voltage, $4.0 \mathrm{kV}$; probe heater temperature, $275^{\circ} \mathrm{C}$; S-lens $70 \mathrm{~V}$. Target lipids were analyzed with a mass range of $\mathrm{m} / \mathrm{z} 350$ 2,000 (resolving power 70,000 at $\mathrm{m} / z 200$ ), followed by datadependent tandem $\mathrm{MS}^{2}$ (resolving power 17,500), in which the 10 most abundant masses in the mass spectrum were fragmented successively (stepped normalized collision energy 15, 22.5, 30; isolation width $1.0 \mathrm{~m} / \mathrm{z}$ ). The Q Exactive was calibrated within a mass accuracy range of $1 \mathrm{ppm}$ using the Thermo Scientific Pierce LTQ Velos ESI Positive Ion Calibration Solution. During analysis dynamic exclusion was used to temporarily exclude masses (for $6 \mathrm{~s}$ ) in order to allow selection of less abundant ions for $\mathrm{MS}^{2}$. 


\section{Compound Isolation and NMR Analysis}

Specific IPLs were isolated from Bligh-Dyer extracts of $M c$. alkaliphilus $\mathrm{AMF}^{\mathrm{T}}$ biomass using an Agilent Technologies (Santa Clara, CA) 1100 series HPLC with a thermostatted autoinjector, column oven, and a Foxy Jr. fraction collector (Teledyne Isco, Lincoln, NE, USA). Aliquots of filtered BlighDyer extract $(200 \mu \mathrm{L})$ were injected onto a LiChrospher DIOL column $(250 \mathrm{~mm} \times 10 \mathrm{~mm}, 10 \mu \mathrm{m}$ : Alltech, Deerfield, IL), all fractions were eluted using the identical gradient and mobile phase composition described above for the HPLCITMS analysis, but at a flow rate of $3 \mathrm{~mL} \mathrm{~min}^{-1}$. The column effluent was collected in $3 \mathrm{~mL}$ fractions. Fractions from semipreparative HPLC were screened for the presence of the target compound with flow injection analysis using HPLC-ITMS as described above, and the fractions containing the target compound were pooled. For further purification the combined fractions were re-injected and column effluent was collected in $15 \mathrm{~s}$ fractions.

$N, N, N$,-trimethyl aminopentanetetrol (APT)-AR and an unknown lipid (referred to below as IIa) were dissolved in 500 $\mu \mathrm{L} 99.9 \% \mathrm{CDCl}_{3}$ at concentrations of 3.0 and $0.8 \mathrm{mg} \mathrm{ml}^{-1}$, and NMR experiments were performed at $298 \mathrm{~K}$ on a Bruker 900-MHz Avance III spectrometer equipped with $5 \mathrm{~mm}$ TCI cryoprobe, running under TOPSPIN 3.2. One-dimensional (1D) ${ }^{1} \mathrm{H}$ and ${ }^{1} \mathrm{H}$-decoupled $1 \mathrm{D}{ }^{13} \mathrm{C}$ and Distortionless Enhancement by Polarization Transfer (DEPT)-135 experiments were recorded with spectral widths/offsets of $20 \mathrm{ppm} / 4.7 \mathrm{ppm}, 200 \mathrm{ppm} / 100$ ppm, and $200 \mathrm{ppm} / 100 \mathrm{ppm}$ and with 16,384 (16 k), 4,096 (4k), and 4,096 (4k) complex points, respectively. 12- by 12-ppm 2D correlation spectroscopy (COSY), total correlation spectroscopy (TOCSY), and nuclear Overhauser effect spectroscopy (NOESY) experiments were performed with 512 by 256 complex points (by 200 for the NOESY) and an offset frequency of $4.7 \mathrm{ppm}$. Mixing times were 60 and $120 \mathrm{~ms}$ for TOCSY and $250 \mathrm{~ms}$ for NOESY experiments. $\left({ }^{1} \mathrm{H},{ }^{13} \mathrm{C}\right)$-heteronuclear single-quantum correlation spectroscopy (HSQC) and $\left({ }^{1} \mathrm{H},{ }^{13} \mathrm{C}\right)$-heteronuclear multiple-bond correlation spectroscopy (HMBC) experiments were recorded with spectral widths/offsets of $12 / 4.7 \mathrm{ppm}$ for protons, 200/100 ppm for ${ }^{13} \mathrm{C}$ HSQC (512 x 64 complex points) and $150 / 75 \mathrm{ppm}$ for the $\operatorname{HMBC}(1 \mathrm{k} \times 80$ complex points). All spectra were calibrated with respect to internal residually protonated $\mathrm{CHCl}_{3}$ at $7.24 \mathrm{ppm}\left({ }^{1} \mathrm{H}\right)$ and 77.0 $\operatorname{ppm}\left({ }^{13} \mathrm{C}\right)$.

\section{Genomic and Phylogenetic Analyses}

Partial 16S rRNA gene sequences of the strains mentioned in the manuscript and others were obtained from the Silva 128 release (https://www.arb-silva.de/). A phylogenetic tree of $16 \mathrm{~S}$ rRNA gene sequences was inferred with the Neighbor-Joining method (Saitou and Nei, 1987) in MEGA6 (Tamura et al., 2013). The evolutionary distances were computed using the JukesCantor method (Jukes and Cantor, 1969). The analysis involved 29 nucleotide sequences with a total of 1,185 positions in the final dataset.

Putative polyprenyl synthase coding genes were identified in the available genomes of the studied strains along with a selection of other archaea with PSI-BLAST (Position-Specific iterated BLAST) searches at the protein level (www.ncbi.com) using two iteration steps using the annotated geranylfarnesyl disphosphate synthase of Aeropyrum (A.) pernix [accession number Q9UWR6.1; (Tachibana et al., 2000)] as query sequence and limiting the search to hits with percentage of identity higher than $20 \%$ and $e$-value $<1 \times 10^{-30}$. Putative polyprenyl synthases were aligned by Muscle (Edgar, 2004) in the MEGA6 software (Tamura et al., 2013) and edited manually. Phylogenetic reconstruction was performed by maximum likelihood in the MEGA 6 software (Tamura et al., 2013) based on the JTT matrix-based model (Jones et al., 1992). A discrete Gamma distribution was used to model evolutionary rate differences among sites ( 5 categories, $+\mathrm{G}$ parameter $=1.5942$ ). The rate variation model allowed for some sites to be evolutionarily invariable $([+I], 4.2308 \%$ sites $)$. The tree was drawn to scale, with branch lengths measured in the number of substitutions per site. The analysis involved 49 amino acid sequences. There was a total of 421 positions in the final dataset.

\section{RESULTS}

Thirteen strains of haloarchaea isolated from hypersaline soda lakes were compared for the composition of their membrane lipids. The strains were separated into three groups based on their physiology: 4 methanogens, 5 polysaccharide utilizers and 4 sulfur-respiring haloarchaea (Table 1).

\section{Core Lipid Composition}

The ether lipids detected by GC-MS and HPLC-APCI/MS were all normalized to $\mathrm{AR}$ and combined to give the estimated distribution of all hydrolysis-derived ether core lipids (Table 2). In 12 of the 13 strains, AR was either a dominant (73-88\%) or major (20-58\%) component, whereas in one polysaccharide utilizing, moderately alkaliphilic strain, AArcel7, AR was only present as a minor component (12\%). Two forms of EXTAR in both $\mathrm{C}_{20-25}$ and $\mathrm{C}_{25-20}$ configurations (with different $s n 2$ and $s n 3$ arrangements) were detected. Ms. natronophilum $\mathrm{AME} 2^{\mathrm{T}}$ was found to contain hydroxy archaeols (OH-AR; 15\%) and the macrocyclic AR (MAR; 6\%), neither of which were detected in any other strains. Four different phytanyl glycerol monoethers were detected, the sn2- and sn3- alkyl glycerol monoether, in both the $\mathrm{C}_{20}$ and $\mathrm{C}_{25}$ forms. These did not constitute more than $16 \%$ of the diethers, except in the case of moderately alkaliphilic chitinolytic strain "Na. haloalkaliphilus" AArcht-Sl ${ }^{\mathrm{T}}$, where $\mathrm{C}_{25}$ (extended) $s n$-3-alkyl glycerol ether was present as $49 \%$ of the diether fraction. We have interpreted the four alkyl glycerol monoethers as artifacts that are formed during acid hydrolysis from diether lipids containing unsaturated alkyl moieties (de Souza et al., 2009) as confirmed by the IPL measurements (see section IPLs). GDGT-0 and GDGT-1 were detected in the methanogenic strains, but not in the members of Halobacteria. GDGT-0 accounted for 59 and $79 \%$ of the total core lipids in the two extremely halophilic methanogens from the class Methanonatronarchaeia, alkaliphilic Mn. thermophilum $\mathrm{AMET1}^{\mathrm{T}}$ and neutrophilic "Ca. Mh. thermophilum" HMET1, while GDGT-1 was $7 \%$ in the former but absent in the latter. In 
the two haloalkaliphilic members of the class Methanomicrobia, Ms. natronophilum $\mathrm{AME}^{\mathrm{T}}$ and Mc. alkaliphilus $\mathrm{AMF} 2^{\mathrm{T}}$, GDGT0 accounted for 17 and 15\% while GDGT-1 was present at 1 and $<0.1 \%$, respectively.

\section{IPLs}

Analysis by HPLC-ITMS (e.g., Figure 2) and UHPLC-HRMS of the Bligh-Dyer extracts of the 13 strains resulted in the identification of a wide range of IPLs, including novel compounds. We describe these in three sections: diethers, ether analogs of cardiolipins and GDGTs.

\section{Diether IPLs}

Diether IPLs detected by HPLC-ITMS (see Table S1 for all species detected, structures in Figure 3) contained the following polar headgroups: phosphatidylethanolamine (PE), phosphatidylglycerol (PG), phosphatidylglycerophosphate (PGP), and its methyl ester (PGP-Me), APT [with tri-, di- and mono-N-methylations), phosphatidylinositol (PI), phosphatidylserine (PS), phosphatidylglycerosulfate (PGS), and dihexose (2Gly, also known as DGA-1 in e.g., Kates (1992)]. The core component of the IPLs included AR, EXT$\mathrm{AR}, \mathrm{OH}-\mathrm{AR}$, and MAR (also detected by GC-MS analysis), unsaturated (Uns) forms of both AR and EXT-AR (with between 1 and 8 unsaturations) and $\mathrm{OH}-\mathrm{AR}$ (with between 1 and 5 unsaturations). The diether IPLs (Table S1) were examined in terms of their MS peak area response, which is generally dependent on polar group ionization and therefore do not reflect the absolute quantities of the different lipids. Besides these known diether species, also a number of novel diether lipids (I-III, Figure 2) were detected. Their identification using combinations of $\mathrm{MS}^{2}$ fragmentation, accurate mass and NMR spectroscopy is described below.

\section{Novel diether lipids Ia and Ib}

Two of the alkaliphilic polysaccharide utilizing strains, $\mathrm{Nb}$. cellulositropha AArcel5 ${ }^{\mathrm{T}}$ and strain AArcel7 contained lipids (e.g., Ia and Ib, Figure 2) with parent ions appearing in MS spectra at $m / z 1039.7$ and 969.7, respectively. For both parent ions, upon $\mathrm{MS}^{2}$ fragmentation, a loss of $162 \mathrm{Da}$ (loss of hexose) was observed, generating product ions at $\mathrm{m} / z$ 877.8 (Figure 4A) and 807.8 (Figure 4C), respectively. These product ions match the $m / z$ value of the protonated molecules $\left([\mathrm{M}+\mathrm{H}]^{+}\right.$; Table S1) of PG-EXT-AR and PG-AR, respectively. Indeed, upon further fragmentation in $\mathrm{MS}^{3}$, product ions representing the EXT-AR $(\mathrm{m} / \mathrm{z}$ 723.7, Figure 4B) and $\mathrm{AR}(\mathrm{m} / \mathrm{z}$ 653.6, Figure 4D) core lipids were observed. Therefore, we identified these lipids as phosphatidylglycerohexose-EXT-AR (PG-Gly-EXT-AR, Ia) and phosphatidylglycerohexose-AR (PG-Gly-AR, Ib). This headgroup combined with a diacyl core lipid has been described in halophilic gammaproteobacterium of the genus Halomonas (Giordano et al., 2007), while a very similar diether phosphoglycolipid attached to a sulfated sugar moiety was identified in the alkaliphilic haloarchaeon Natrononomonas (N.) moolapensis (Hoffmann et al., 2015). The position of the sugar of both the bacterial and archaeal glycosylated-PG described in the literature were determined by NMR to be
A Natronobiforma cellulositropha AArce15 ${ }^{\mathrm{T}}$

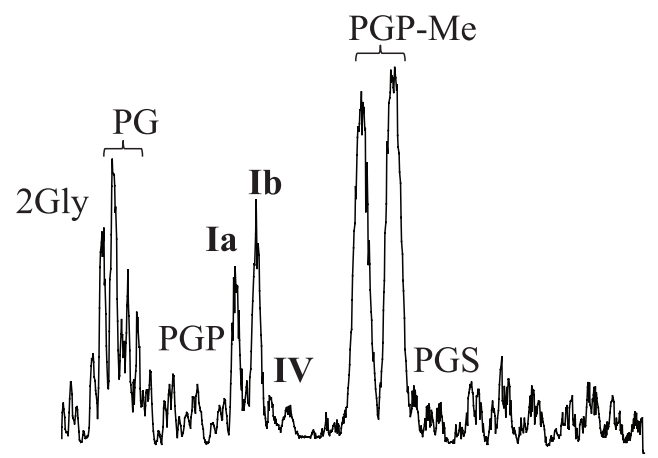

B Methanocalculus alkaliphilus $\mathrm{AMF} 2^{\mathrm{T}}$

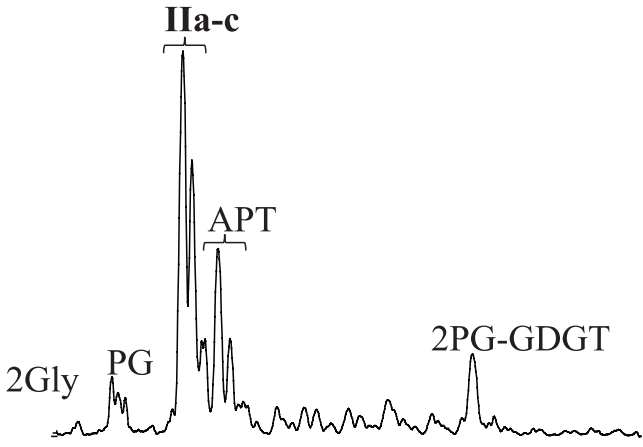

c Halodesulfurarchaeum formicicum HSR6 ${ }^{\mathrm{T}}$

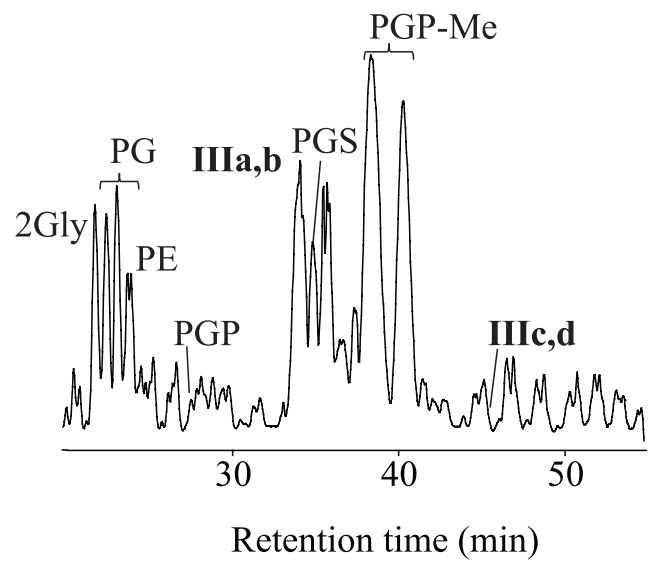

FIGURE 2 | Partial base peak chromatogram (Gaussian smoothed) of the HPLC-ITMS analysis of IPLs in three strains of haloarchaea: (A) Natronobiforma cellulositropha AArcel5, (B) Methanocalculus alkaliphilius AMF2T, (C) Halodesulfurarchaeum formicicum HSR6T. For abbreviations of IPL names see text.

at the 2-glycero position (Giordano et al., 2007; Hoffmann et al., 2015). In our study the $\mathrm{MS}^{2}$ fragmentation pattern could not confirm whether the hexose was at the 1- or 2glycerol position, but the similarity of the PG-Gly spectra 
Polar head groups

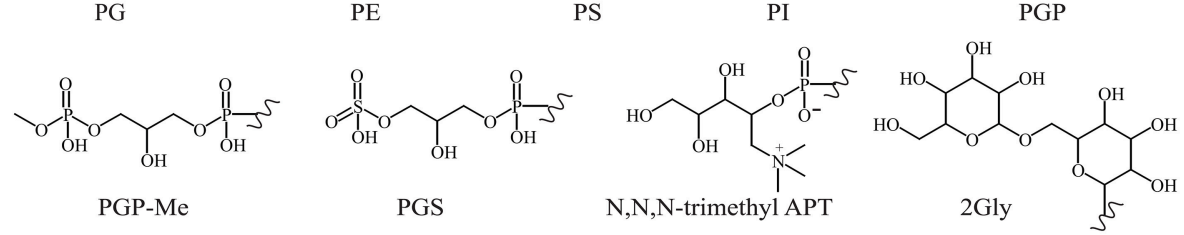

Dialkyl glycerol diether core lipids<smiles>[R10]CCC(C)CCCC(C)CCCC(C)CCCC(C)CCCC(C)CCCC(C)CCCC(C)CCCC(C)C</smiles>

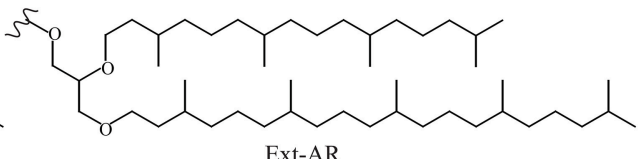

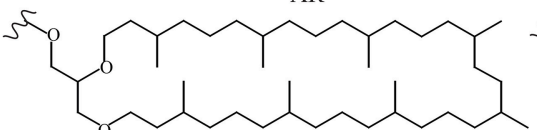

MAR Ext-AR

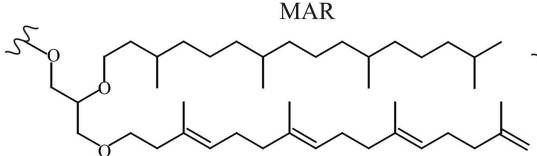

Uns(4)-AR

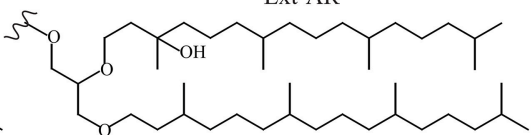

$\mathrm{OH}-\mathrm{AR}$

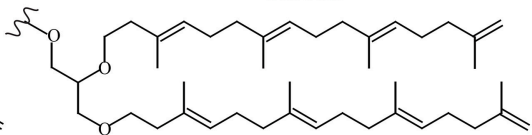

Uns(8)-AR

Glycerol dialkyl glycerol tetraether core lipids

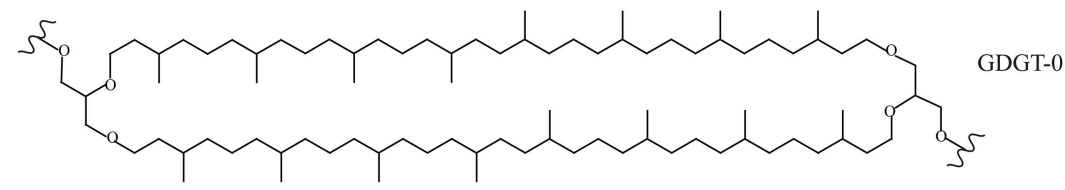

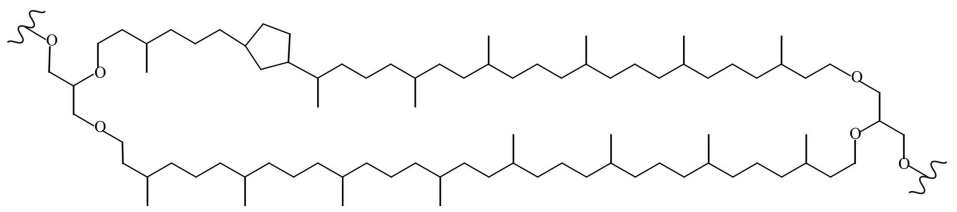

GDGT-1

FIGURE 3 | Structures of known polar headgroups and core lipids described in this study. Polar headgroups: PE, phosphatidylethanolamine; PS, phosphatidylserine; PI, phosphatidylinositol; PG, phosphatidylglycerol; PGP, phosphatidylglycerophosphate; PGP-Me, phosphatidylglycerophosphate methyl ester; PGS, phosphatidylglycerosulfate; trimethyl APT, N,N,N-trimethyl aminopentanetetrol (for other methylations see Figure 5); 2Gly, dihexose. Dialkyl glycerol diether core lipids; AR, archaeol; EXT-AR, extended archaeol; MAR, macrocyclic archaeol; OH-AR, hydroxy archaeol; Uns, unsaturated. Glycerol dialkyl glycerol tetraether core lipids (GDGTs, where $n$ is the number of cyclopentane moieties).

with those of 1-(6-sulfo-D-glcp/galf- $\beta 1,2$-glycero)-phospho2,3-diphytanylglycerol found in $N$. moolapensis (Hoffmann et al., 2015) provides an indication that they both have same structural arrangement.

\section{Novel N,N,N-trimethyl APT derivatives}

The dominant but unknown IPL in Mc. alkaliphilus $\mathrm{AMF}^{\mathrm{T}}$ (IIa, Figure 2) exhibited a parent ion at $m / z$ 923.0 during HPLC-ITMS analysis. Upon UHPLC-HRMS analysis it was found to have an accurate mass of 922.7816 (Table S2). Upon UHPLC-HRMS fragmentation, product ions at $m / z 288.1205,270.1100,208.1544$, and 190.1438 were formed (Figure 5A; Table S2). Both the parent ion and all the main fragments produced are offset by 14
Da compared to the parent ion and fragments of $N, N, N$-trimethyl APT-AR $\left([\mathrm{M}+\mathrm{H}]^{+} m / z\right.$ 908.7666, Table S2). These fragment ions of $N, N, N$-trimethyl APT-AR (Figure 5B) can be interpreted as follows: $m / z 274.1037$ is the intact $N, N, N$-trimethyl APT headgroup, $m / z 256.0953$ is a loss of $\mathrm{H}_{2} \mathrm{O}$ from the $m / z 274.1037$ ion, $m / z 194.1399$ is the headgroup without the phosphate moiety, and $m / z 176.1284$ represents a loss of $\mathrm{H}_{2} \mathrm{O}$ from the $\mathrm{m} / z$ 194.1399 ion. The mass difference between fragments of $N, N, N-$ trimethyl APT and of IIa was always in the range 14.014514.0168 Da which indicates that IIa contains an additional $\mathrm{CH}_{2}$ group $(14.0151 \mathrm{Da})$ in its headgroup, likely by conversion of one of the alcohol groups into a methoxy group, i.e., $N, N, N$-trimethyl aminopentanemethoxytriol (APT-Me). Based 

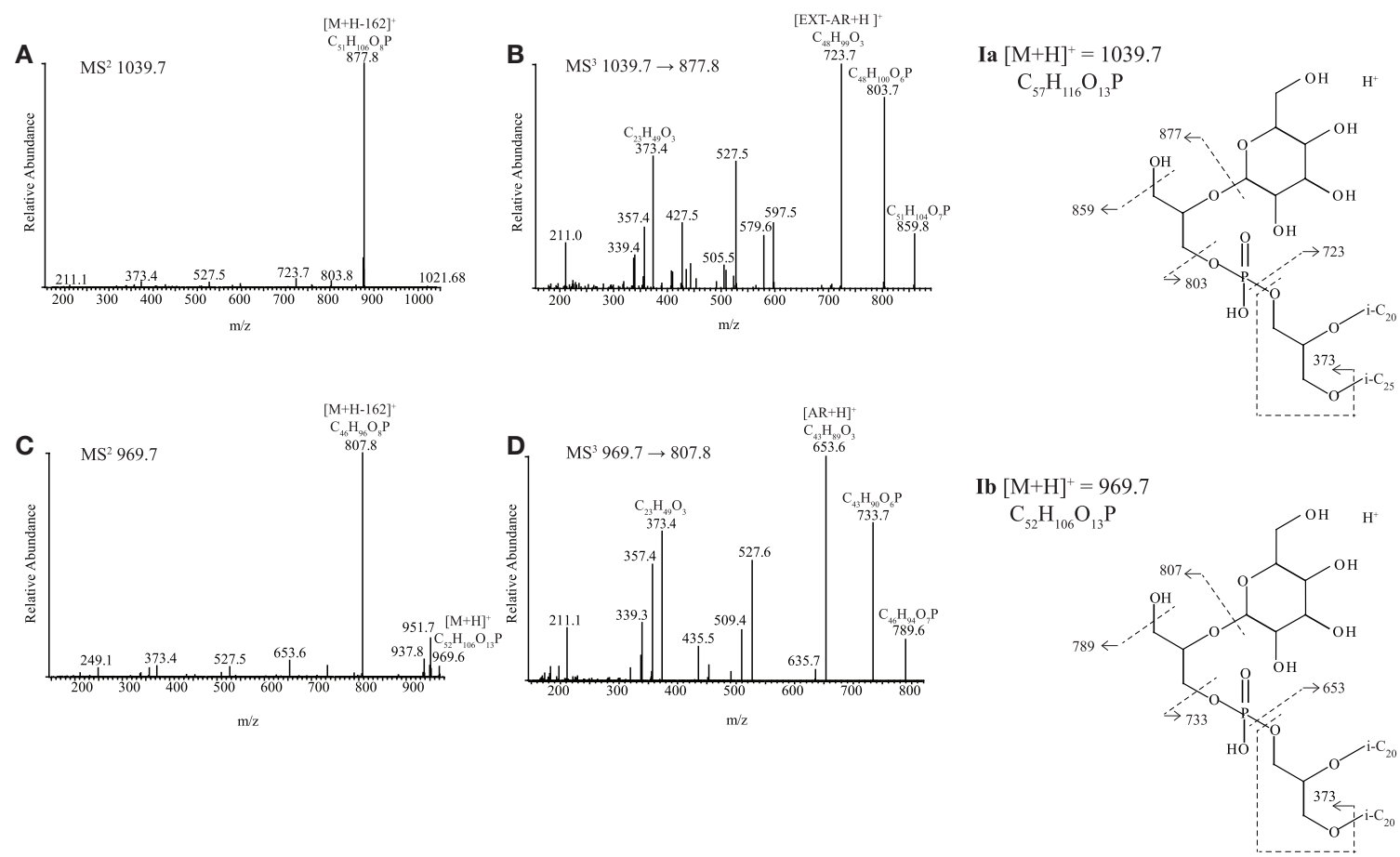

FIGURE 4 | HPLC-ITMS ${ }^{2}$ and $\mathrm{MS}^{3}$ spectra with inserts of structure with fragmentations indicated for (A,B) la PG-Gly-EXT-AR and (C,D) lb PG-Gly-AR. i-C $20, \mathrm{C}_{20}$ isoprenoid chain; $\mathrm{i}-\mathrm{C}_{25}, \mathrm{C}_{25}$ isoprenoid chain.

on this identification, we interpreted the $\mathrm{MS}^{2}$ spectrum of IIa (Figure 5A; Table S2) as follows: $m / z 288.1205$ is the methylated $N, N, N$-trimethyl APT headgroup with the phosphate moiety, $m / z 270.1100$ is loss of $\mathrm{H}_{2} \mathrm{O}$ from the $\mathrm{m} / z 288.1205$ ion, $m / z 208.1544$ is the $N, N, N$-trimethyl APT-Me headgroup without the phosphate moiety, and $m / z 190.1438$ is loss of $\mathrm{H}_{2} \mathrm{O}$ from the $m / z 208.1544$ ion. A series of mono- to octaUns-AR with a $N, N, N$-trimethyl APT-Me headgroup (HPLCITMS $[\mathrm{M}+\mathrm{H}]^{+}$from $\mathrm{m} / z$ 920.9-906.7) exhibited very similar HPLC-ITMS MS ${ }^{2}$ fragmentations (Table S1) with a decreasing intensity of the product ion arising from loss of one alkyl chain, depending on the number of unsaturations. The minor unknowns IIb, IIc were identified using UHPLC-HRMS as $N, N$ dimethyl $(\mathrm{m} / z$ 908.7661, Figure 5C) and N-monomethyl APTMe-AR ( $m / z$ 894.7506, Figure 5E), analogous to $N, N$-dimethyl APT-AR $(m / z$ 894.7510, Figure 5D) and N-monomethyl APT$\operatorname{AR}(m / z$ 880.7349, Figure 5F).

In order to confirm the identification of the novel $N, N, N$ trimethyl APT-Me derivatives IIa-c and to assess the position of the Me group on the pentanetetrol moiety, the most abundant IPL of this series, IIa, was purified using semi-preparatory HPLC in order to carry out analysis by NMR spectroscopy. The putative $N, N, N$-trimethyl APT-AR was also purified and analyzed by NMR spectroscopy for comparison. Both $N, N, N$-trimethyl APT$A R$ and IPL IIa exhibited similar NMR spectra with almost identical ${ }^{13} \mathrm{C}$ - and ${ }^{1} \mathrm{H}$-NMR shifts for most of carbon and proton atoms, including those of the polar headgroup (Table S3). The ${ }^{13} \mathrm{C}$ - and ${ }^{1} \mathrm{H}$-shifts associated with the glycerol unit and the phytanyl chains were identified in comparison with those described for GDGTs (Sinninghe Damsté et al., 2002) and are not presented here. The ${ }^{13} \mathrm{C}$ - and ${ }^{1} \mathrm{H}$-NMR shifts reported by Ferrante et al. (1987) for N,N,N-trimethyl APT are similar to ours and the few differences that occur can all be accounted for by the differences in solvent and experimental conditions used (e.g., ${ }^{2} \mathrm{H}_{2} \mathrm{O}$ and benzene- $d_{6} /$ methanol- $d_{4}$ vs. $\mathrm{CDCl}_{3}$ used in this study). Whereas, the $N, N, N$-trimethyl APT headgroup exhibits 6 carbon signals for its polar headgroup, that of the putative $N, N, N$-trimethyl APT-Me IPL exhibited seven carbon signals, confirming that the additional $14 \mathrm{Da}$ was due to an additional $\mathrm{C}$ atom and its associated protons. This additional $\mathrm{C}$ atom $\left(\mathrm{C}_{7}\right.$; Table S3) was determined by a DEPT experiment to be either a primary or tertiary carbon. HSQC analysis provided evidence for a single signal at $3.36 \mathrm{ppm}$, indicative of a primary methyl group. Furthermore, its ${ }^{13} \mathrm{C}$ shift at $59 \mathrm{ppm}$ agrees with a methoxy group and hence it was assigned to be an $N, N, N$ trimethyl APT-Me. The carbon and associated proton signals of three carbon atoms $\left(\mathrm{C}_{1}, \mathrm{C}_{2}, \mathrm{C}_{6}\right)$ of the $N, N, N$-trimethyl APTMe headgroup were almost identical to those of $N, N, N$-trimethyl APT-AR (Table S3), which provides evidence the additional $\mathrm{CH}_{3}$ group $\left(\mathrm{C}_{7}\right)$ was bound to an oxygen atom at either $\mathrm{C}_{3}, \mathrm{C}_{4}$, or $\mathrm{C}_{5}$. The $\mathrm{HMBC}$ spectrum provided confirmation that $\mathrm{C}_{7}$ was in fact bound to the oxygen at $\mathrm{C}_{5}$ as the protons at $\mathrm{C}_{7}$ interacted most strongly with those of $\mathrm{C}_{5}$ (see structure insert Table S3). Further confirmation of the structure from the $\mathrm{HMBC}$ spectrum were the cross peaks between the protons of $\mathrm{C}_{6}$ with those of $\mathrm{C}_{1}$, and those of $\mathrm{C}_{1}$ with both $\mathrm{C}_{6}$ and $\mathrm{C}_{3}$ and from the COSY spectrum that indicated that the protons of $\mathrm{C}_{2}$ were $J$-coupled with $\mathrm{C}_{3}$. 

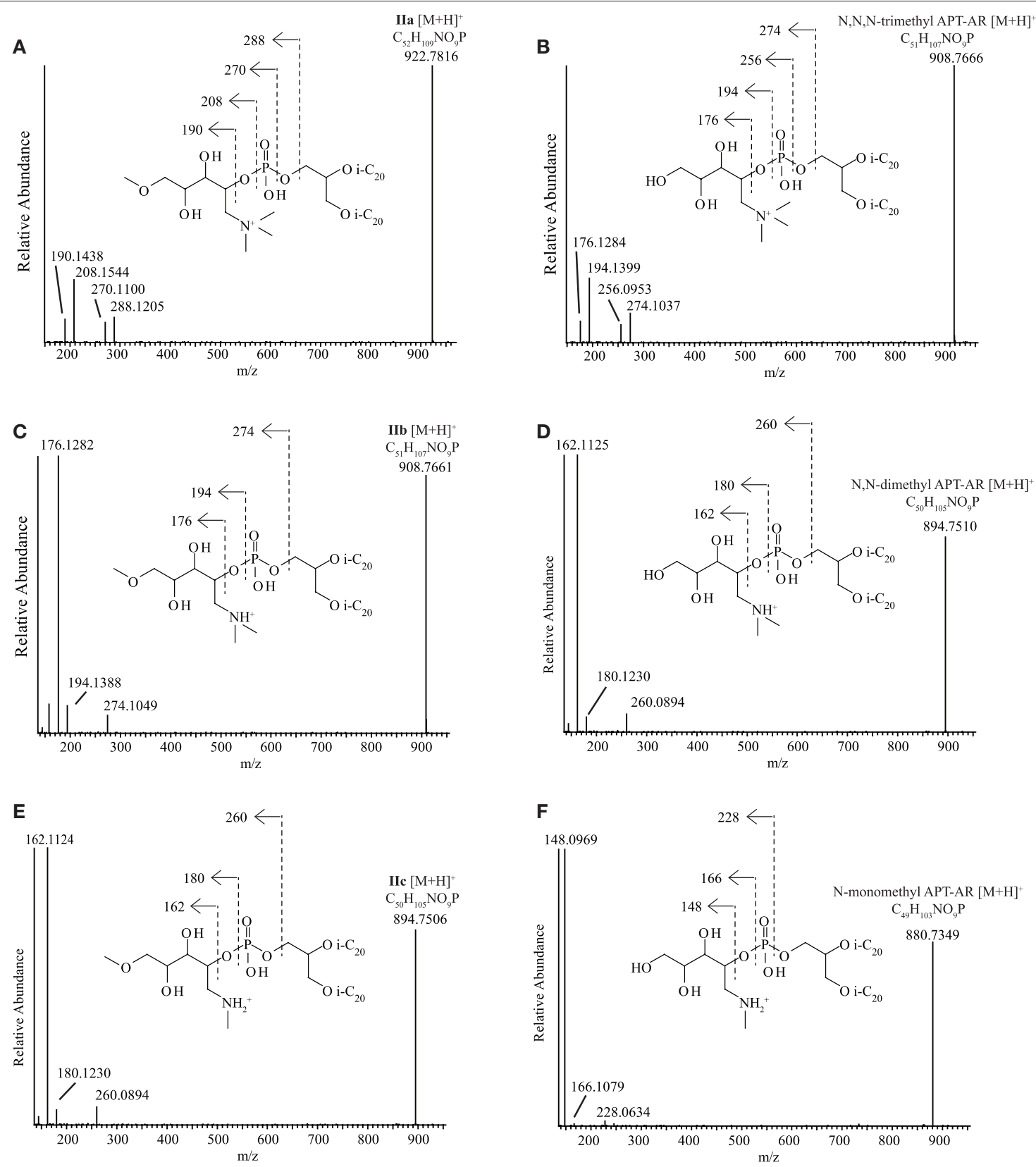

FIGURE 5 | UHPLC-HRMS MS ${ }^{2}$ spectra with structures and fragmentations indicated for (A) N,N,N-trimethyl aminomethoxypentanetriol (trimethyl APT-Me, Ila), (B) $\mathrm{N}, \mathrm{N}, \mathrm{N}$-trimethyl aminopentanetetrol (trimethyl APT), (C) N,N-dimethyl aminomethoxypentanetriol (dimethyl APT-Me, Ilb), (D) N,N-dimethyl aminopentanetetrol (dimethyl APT), (E) N-monomethyl aminomethoxypentanetriol (monomethyl APT-Me, IIc), (F) N-monomethyl aminopentanetetrol (monomethyl APT). i-C $20, \mathrm{C}_{20}$ isoprenoid chain.

\section{Diethers with novel sulfur-containing headgroups (IIIa-d)}

Four unknown IPLs with two closely related headgroups were detected in four strains (all neutrophilic) distributed across all three archaeal metabolic groups, namely in methanogenic ' $\mathrm{C}$. Mh. thermophilum' HMET1, cellulolytic "Hc. cellulosivorans" $\mathrm{HArcel}^{\mathrm{T}}$ and sulfur-respiring $\mathrm{Hd}$. formicicum $\mathrm{HSR}^{\mathrm{T}}$ and Hn. sulfurireducens $\mathrm{HSR}^{\mathrm{T}}{ }^{\mathrm{T}}$. During HPLC-ITMS analysis, two compounds with the same headgroup, IIIa, and IIIb produced
$\left[\mathrm{M}+\mathrm{NH}_{4}\right]^{+}$ions at $\mathrm{m} / z 1091.5$ and 1161.5 , and two with a closely related headgroup (IIIc and IIId) produced $\left[\mathrm{M}+\mathrm{NH}_{4}\right]^{+}$at $\mathrm{m} / z$ 1171.4 and 1241.4 (Figure 6). Structural identification using UHPLC-HRMS resulted in the partial elucidation of the structure of these unknown headgroups (accurate masses of the parent ions and fragments are given in Table S4). The $\mathrm{MS}^{2}$ spectrum (Figure 6A) of IIIa possessing a $\left[\mathrm{M}+\mathrm{NH}_{4}\right]^{+}$of $\mathrm{m} / z 1091.7936$ ion exhibited a loss of $\mathrm{SO}_{3}$ and $\mathrm{NH}_{3}$ from the $\left[\mathrm{M}+\mathrm{NH}_{4}\right]^{+}$to 
produce a fragment ion at $\mathrm{m} / \mathrm{z} 994.8116$. The ion at $\mathrm{m} / \mathrm{z} 832.7605$ was interpreted as the loss of hexose $\left(\mathrm{C}_{6} \mathrm{H}_{10} \mathrm{O}_{5}, 162.0523 \mathrm{Da}\right)$ from the ion at $m / z$ 994.8116. A further loss of $\mathrm{C}_{6} \mathrm{H}_{10} \mathrm{NO}_{5}$ from the $m / z 832.7605$ ion produced the most abundant product ion at $m / z 653.6800$ representing the AR core lipid). The fragment ion $m / z 373.3675$ was assigned as a phytanyl moiety attached to a glycerol moiety $\left(\mathrm{C}_{23} \mathrm{H}_{49} \mathrm{O}_{3}\right)$. The elemental composition of this compound, taken in combination with its $\mathrm{MS}^{2}$ fragmentation allowed us to propose a putative structure of IIIa as having a headgroup with elemental composition $\mathrm{C}_{12} \mathrm{H}_{25} \mathrm{NO}_{13} \mathrm{~S}$ and an AR core (Figure 6A; Table S4). The second IPL with the same headgroup, IIIb, possessed a $\left[\mathrm{M}+\mathrm{NH}_{4}\right]^{+}$ion at $\mathrm{m} / z 1161.8720$ and exhibited similar losses in its $\mathrm{MS}^{2}$ spectrum (Figure 6B and Table S4): loss of $\mathrm{SO}_{3}$ and $\mathrm{NH}_{3}$ from the $\left[\mathrm{M}+\mathrm{NH}_{4}\right]^{+}$to produce a fragment ion at $\mathrm{m} / \mathrm{z} 1064.8916$, sequential losses of hexose and $\mathrm{C}_{6} \mathrm{H}_{10} \mathrm{NO}_{5}$ group to produce ions at $\mathrm{m} / z 902.8398$ and 723.7582, respectively. The smaller fragment ions were assigned a phytanyl moiety attached to a glycerol moiety $(\mathrm{m} / z$ 373.3676, $\mathrm{C}_{23} \mathrm{H}_{49} \mathrm{O}_{3}$ ) and the corresponding $\mathrm{C}_{25}$ isoprenoid alkyl chain attached to a glycerol moiety $\left(m / z 443.4470, \mathrm{C}_{28} \mathrm{H}_{59} \mathrm{O}_{3}\right)$. Based on accurate mass determination of fragments and losses the IIIb compound was identified as having a $\mathrm{C}_{12} \mathrm{H}_{25} \mathrm{NO}_{13} \mathrm{~S}$ headgroup with an EXT-AR core.

IIIc and IIId produced similar $\mathrm{MS}^{2}$ spectra to IIIa and IIIb (Figures 6C,D and Table S4), but IIIc and IIId contained an additional $\mathrm{SO}_{3} \mathrm{H}$ group (based on UHPLC-HRMS ${ }^{2}$ fragmentation, Table S4) on the polar headgroup. Hence, they were assigned as a $\mathrm{C}_{12} \mathrm{H}_{25} \mathrm{NO}_{16} \mathrm{~S}_{2}$ headgroup with either an $\mathrm{AR}$ (Figure 6C) or EXT-AR (Figure 6D) core. The exact position(s) of the $\mathrm{SO}_{3} \mathrm{H}$ group(s) could not be established. Biomass was not available in great enough quantity to carry out the compound isolation that would be required for NMR analysis.

\section{Ether Analogs of Cardiolipins}

Ether analogs of cardiolipins, with two dialkyl glycerol diether cores connected by a polar moiety, were detected in four of the 13 strains (Table 3, Table S1). Two of these cardiolipins were identified as bisphosphatidylglycerols (BPGs) containing two AR cores (Figure 7A) and a BPG with an AR and an EXTAR core (Figure 7B). These IPLs have been reported previously in other haloarchaea (Lattanzio et al., 2002; Corcelli, 2009; Angelini et al., 2012; Lobasso et al., 2015). Three novel tetraether cardiolipins (IVa-c) were found in three polysaccharide utilizing alkaliphilic haloarchaeal strains, "Na. chitinivorans" AArcht 4 T, $\mathrm{Nb}$. cellulositropha AArcel5 $5^{\mathrm{T}}$ and AArcel7. They exhibited $[\mathrm{M}+\mathrm{H}]^{+}$masses $(\mathrm{m} / \mathrm{z} 1676.4,1746.5,1816.6)$ identical to those of a series of unknown cardiolipins from the cell membrane of two species of alkaliphilic haloarchaea from the alkaliphilic genus Natronococcus that were previously reported by Angelini et al. (2012). While Angelini et al. (2012) postulated these were glycocardiolipins, their $\mathrm{MS}^{2}$ spectra did not support the presence of sugar groups. One of our three novel tetraether cardiolipins (IVa) exhibited a $[\mathrm{M}+\mathrm{H}]^{+}$at $\mathrm{m} / z$ 1676.4. Its $\mathrm{MS}^{2}$ spectrum (Figure 7C) contained product ions at $\mathrm{m} / z$ 1396.0, consistent with a loss of a phytanyl chain $(280 \mathrm{Da})$ and at $\mathrm{m} / z 1023.7$ (loss of AR, $653 \mathrm{Da}$ ). The most abundant ion at $m / z 869.7$ is also present in the $\mathrm{MS}^{2}$ spectrum of AR-PGP-AR (Figure 7A).
In the case of AR-PGP-AR the $\mathrm{m} / z 869.7$ represents a loss of AR (653 Da; Figure 7A), whereas for IVa it represents a loss of $807 \mathrm{Da}$. This additional $154 \mathrm{Da}$ within the polar bridge of the cardiolipin can be explained by an additional glycerophosphate moiety. Hence, we have assigned IVa as containing a putative phosphatidylglycerophosphate glycerophosphate (PGPGP) polar group (Figure 7C). Based on previous nomenclature (e.g., Lattanzio et al., 2002; Corcelli, 2009; Angelini et al., 2012), the novel cardiolipins would be termed bisphosphatidylglycerol glycerophosphates (BPGGPs). A similar tetraether cardiolipin (IVb) exhibited a $[\mathrm{M}+\mathrm{H}]^{+}$at $\mathrm{m} / z$ at $1746.5,70$ Da larger than IVa. This difference in mass suggests the presence of an EXT-AR core instead of an AR core. Indeed, the product ions in the MS ${ }^{2}$ spectrum arising from fragmentation of this ion mirrored the losses seen for IVa cardiolipin with addition of losses associated with an EXT-AR chain (Figure 7D). These were: $\mathrm{m} / z$ 1466.0 (loss of a phytyl chain, $280 \mathrm{Da}$ ), $\mathrm{m} / z$ 1023.7, and 1093.8 (loss of AR, $653 \mathrm{Da}$ and EXT-AR, $723 \mathrm{Da}$, respectively) and four ions at $\mathrm{m} / z$ 807.8, 869.7, 877.8, and 939.7, which represent the AR and EXTAR containing halves of the parent ion, fragmented on either side of the central phosphate group (Figure 7D). Furthermore, the most dominant product ions, at $\mathrm{m} / z 869.6$ and 939.7 were also the dominant ions in the $\mathrm{MS}^{2}$ spectrum of PGP-AR, EXT-AR (Figure 7B). The $[\mathrm{M}+\mathrm{H}]^{+}$of the third novel cardiolipin (IVc) was $140 \mathrm{Da}$ larger than the first, at $\mathrm{m} / z$ 1816.6, in agreement with the presence of two EXT-ARs instead of a single AR-group. The product ions in its $\mathrm{MS}^{2}$ spectrum are interpreted as follows: $\mathrm{m} / \mathrm{z}$ 1536.2: loss of a phytanyl chain of $280 \mathrm{Da}, \mathrm{m} / z$ 1093.8: loss of EXT-AR of $723 \mathrm{Da}$, two ions at $m / z 877.8$ and 939.7, representing the two halves of the parent ion when fragmented at either side of the central phosphate group (Figure 7E). As for compounds IIIad, NMR analysis was not carried out as there was not sufficient biomass for compound isolation.

\section{GDGT-Based IPLs}

We detected membrane-spanning GDGTs in 4 out of the 13 examined halo(alkali)philic euryarchaea, all methanogens (Table 3). These included 2Gly-GDGT-0, PG-GDGT-0-PG, PGGDGT-1-PG, and PG-GDGT-0-PE, identified by comparison of their masses and their diagnostic fragmentation patterns in $\mathrm{MS}^{2}$ with those described in the literature (Rossel Cartes, 2009; Yoshinaga et al., 2011).

\section{DISCUSSION}

A wide range of intact polar dialkyl glycerol diethers, membranespanning GDGTs and cardiolipins were identified in 13 strains of halo(alkali)philic archaea in this study (cf. Table S1). Many of the intact polar diethers detected have been described previously in other haloarchaea. However, some IPLs described in this study have not, to the best of our knowledge, been previously reported. These include an APT-Me polar headgroup, a series of cardiolipins with a PGPGP polar group, a PG-Gly headgroup with an AR core, and AR and EXT-AR combined with headgroups containing a hexose, a $\mathrm{C}_{6} \mathrm{H}_{10} \mathrm{NO}_{5}$ sugar with either one (IIIa,b) or two (IIIc,d) sulfate groups. 

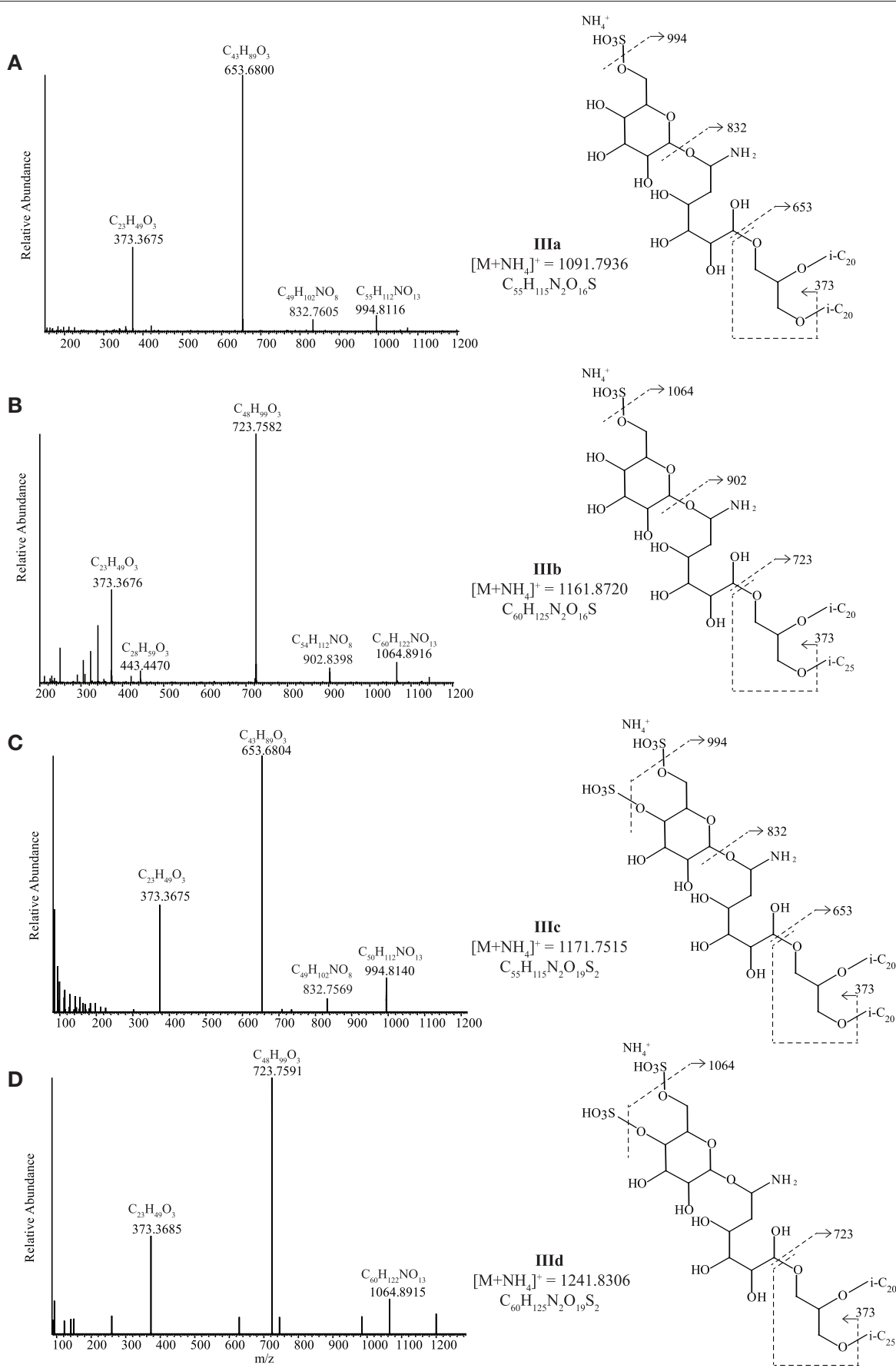

FIGURE 6 | UHPLC-HRMS MS ${ }^{2}$ spectra with putative structures and fragmentations of the $\mathrm{C}_{6} \mathrm{H}_{23} \mathrm{NO}_{13} \mathrm{~S}$ headgroup with (A) an AR core (IIla) and (B) an EXT-AR core (IIIb) and the $\mathrm{C}_{6} \mathrm{H}_{23} \mathrm{NO}_{16} \mathrm{~S}_{2}$ headgroup with (C) an AR core (IIIc) and (D) an EXT-AR core (IIId). i- $\mathrm{C}_{20}, \mathrm{C}_{20}$ isoprenoid chain; i- $\mathrm{C}_{25}, \mathrm{C}_{25}$ isoprenoid chain.

\section{Factors Determining Lipid Composition}

We examined the distribution of membrane lipids across the 13 strains and examined what factors determined their lipid composition. Within the scope of this project it was not possible to carry out controlled culture experiments with varying growth conditions. Hence, here we are limited to hypothesizing on the factors controlling the lipid distributions at fixed growth conditions optimal for each examined strain. Previous studies have examined extensively the impact of phylogeny and physiology on the membrane lipid composition of archaea (Koga et al., 1998; Koga and Nakano, 2008; Elling et al., 2015; Kellermann et al., 2016). It is known that low permeability to water, protons and monovalent cations (i.e., $\mathrm{Na}^{+}$and $\mathrm{K}^{+}$) is the most important membrane adaption 

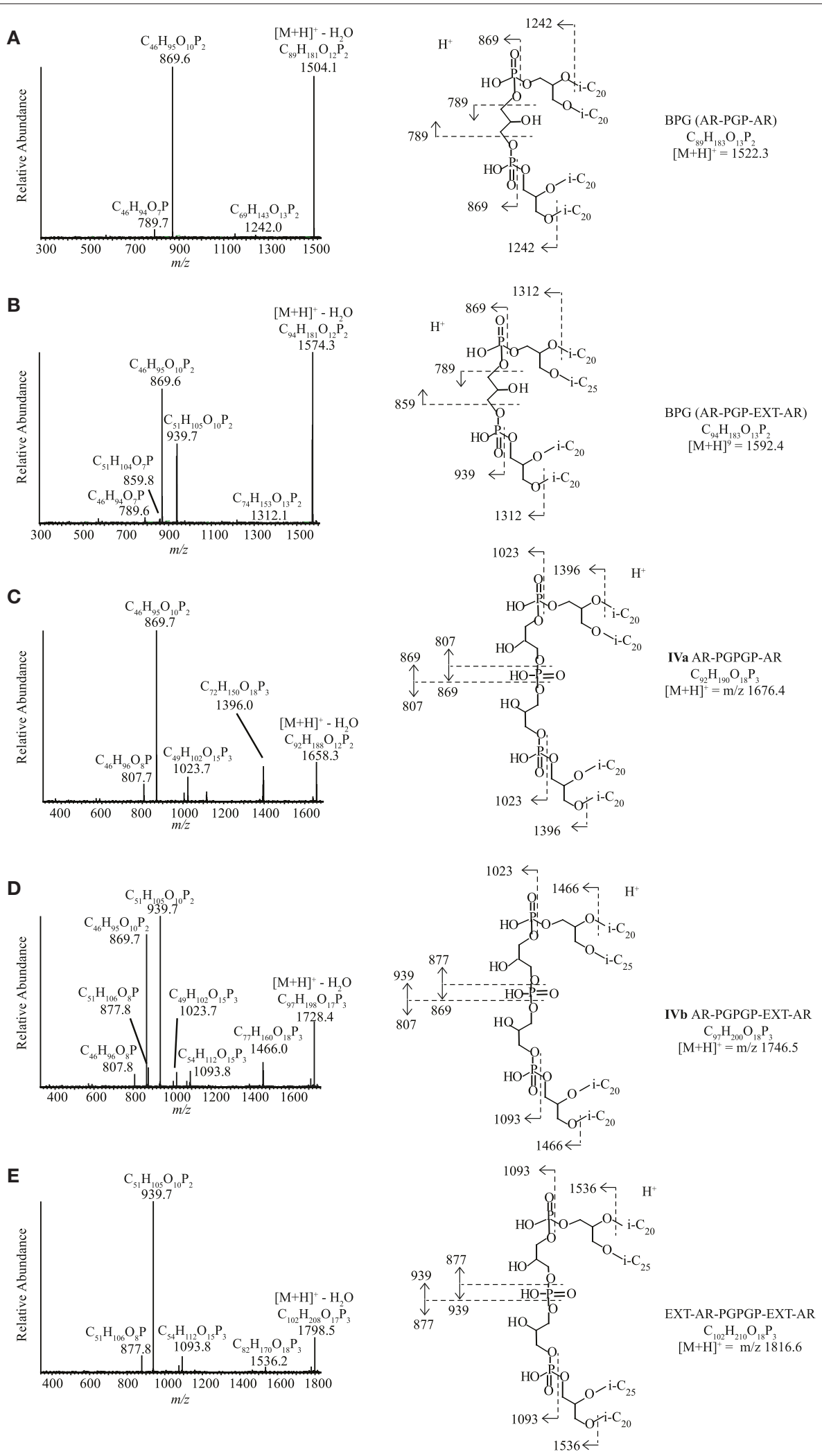

FIGURE 7 | HPLC-ITMS 2 spectra of cardiolipins with putative structures and fragmentations. (A) PGP-AR, AR, (B) PGP-AR, EXT-AR, (C) PGPGP-AR, AR, (D) PGPGP-AR, EXT-AR, and (E) PGPGP-EXT-AR, EXT-AR. i- $\mathrm{C}_{20}, \mathrm{C}_{20}$ isoprenoid chain; i- $\mathrm{C}_{25}, \mathrm{C}_{25}$ isoprenoid chain. 
for haloarchaea (Oger and Cario, 2013). The adaption of haloarchaeal membranes to salt, temperature, oxygen levels, and UV light examined experimentally by Kellermann et al. (2016) allowed them to hypothesize about the function of e.g., different polar headgroups (PG, PGP-Me, and cardiolipins) and core lipid composition. For example, they proposed that by changing the proportion of these polar headgroups, and hence the number of negative charges at its membrane surface, a haloneutrophile can actively balance membrane permeability under varying salt concentrations.

Hereafter, we examine specific lipids and groups of lipids and discuss the possible factors they are associated with, including the phylogenetic relationships between the strains (cf. Figure 1 and Table 1), the three different metabolic processes the 13 strains carry out (methanogenesis, polysaccharide utilization and sulfur respiration) and possible lipid adaptions associated with growth conditions. We have summarized the characteristic lipids associated with these separate factors in Figure 8 and we discuss them in detail in the following sections.

\section{Characteristic Lipids of the Methanogens}

The only characteristic shared by all four methanogens, and not by the other nine strains (all Halobacteria), was the presence of membrane-spanning GDGT lipids (Table 2). This is to be expected since GDGTs have been identified in a wide range of archaea including methanogenic euryarchaea, but not so far in the Halobacteria class [cf. summary tables in Koga et al. (1998) and Schouten et al. (2013)]. PG-GDGT$0-P G$ and PG-GDGT-1-PG were found in three of the four methanogenic strains (Tables 2, S1). 2Gly-GDGT-0 was only detected in neutrophilic "Ca. Mh. Thermophilum" HMET1 (Table S1). 2Gly-GDGTs, including 2Gly-GDGT-0, have been found previously in a wide range of environments (but not in soda lakes), including peat bogs, a suboxic water column and various marine benthic ecosystems (Lipp et al., 2008; Rossel et al., 2008; Lipp and Hinrichs, 2009; Schubotz et al., 2009; Liu et al., 2010; Yoshinaga et al., 2012; Gibson et al., 2013), and while 2GlyGDGT-0 has been identified in cultures of Methanobacterium thermoautotrophicum (Koga et al., 1993), it has also been found in Thaumarchaeota (Schouten et al., 2008; Pitcher et al., 2011). As we discuss further in section Neutrophilic strains, the presence of this sugar headgroup may relate to the neutrophilic nature of HMET1 (cultured at pH 7, Table 1). PG-GDGT-0-PE was only found in $M n$. thermophilum $\mathrm{AMET1}^{\mathrm{T}}$, grown optimally at moderately thermophilic conditions in addition to salinity and pH extremes. PG-GDGT-PE has been previously described in two methane-rich seep environments, where it was specifically associated with anaerobic methane-oxidizing archaea of the ANME-1 cluster (Rossel et al., 2011).

Within the methanogens there was a division between the two classes based on the ratio of GDGTs to AR (cf. Figure 8). The two members of Methanonatronarchaeia ("Ca. Mh. thermophilum" HMET1 and $M n$. thermophilum AMET1 ${ }^{\mathrm{T}}$ ) contained more GDGT than AR (GDGT0+GDGT1/AR $=4$ and 2, respectively) while the two members of the class Methanomicrobia (Ms. natronophilum $\mathrm{AME}^{\mathrm{T}}$ and $M c$. alkaliphilus $\mathrm{AMF} 2^{\mathrm{T}}$ ) contained more AR than GDGTs (ratio values 0.4 and 0.2 , respectively).
This difference may be an adaption to external salt concentration: while the two Methanonatronarchaeia are extremely halophilic methanogens (both cultured at $4 \mathrm{M} \mathrm{Na}^{+}$), the Methanomicrobia are haloalkaliphiles, in that Ms. natronophilum $\mathrm{AME} 2^{\mathrm{T}}$ is an extremely salt-tolerant alkaliphile (cultured at $2 \mathrm{M}$ total $\mathrm{Na}^{+}$), while $M c$. alkaliphilus $\mathrm{AMF} 2^{\mathrm{T}}$ is a moderately salt-tolerant alkaliphile (cultured at $0.6 \mathrm{M}$ total $\mathrm{Na}^{+}$). The presence of GDGTs in the membrane of methanogens may be associated with the reduction of wasteful ion cycling under chronic energy stress conditions (Valentine, 2007), as tetraether-containing membranes are less permeable to ions than purely diether-based membranes (Mathai et al., 2001; Shinoda et al., 2005).

The polar headgroup PS was present in alkaliphilic members of Methanonatronarchaeia (Mn. thermophilum AMET1 ${ }^{\mathrm{T}}$ ) and Methanosarcinales (Ms. natronophilum $\mathrm{AME}^{\mathrm{T}}$ ), but it was absent in any members of the Halobacteria. This polar headgroup has been described previously in a wide range of methanogenic archaea (Koga et al., 1993, 1998; Koga and Morii, 2005), and its presence in Ms. natronophilum AME2 ${ }^{\mathrm{T}}$, a member of Methanosarcinales, and absence in Mc. alkaliphilus $\mathrm{AMF}^{\mathrm{T}}$, belonging to Methanomicrobiales, agrees with the findings of Koga et al. (1998). While PI was only detected in Methanosarcinales member Ms. natronophilum $\mathrm{AME} 2^{\mathrm{T}}$, this polar headgroup has been identified across a wide range of phyla and is not specific to methanogenic euryarchaea (Koga et al., 1993; Koga and Morii, 2005; Oger and Cario, 2013). However, the combination of the PI headgroup with the OH-AR and Uns(1-5)-OH-AR cores (cf. Table S1) is much less common. IPLs containing OH-AR and Uns(n)-OH-AR have been detected in deep-sea cold seep sediments (Yoshinaga et al., 2011), in the crenarchaeon Sulfolobus (S.) acidocaldarius (Sprott et al., 1997), the methanogen Methanosarcina (M.) barkeri (Nishihara and Koga, 1991) and in the extreme cold-adapted methanogen Methanococcoides (M.) burtonii (Nichols et al., 2004). M. barkeri, M. burtonii, and Ms. natronophilum $\mathrm{AME}^{\mathrm{T}}$ are all members of the Methanosarcinales order, which suggests that $\mathrm{OH}-\mathrm{AR}$ and Uns(n)-OH-AR may be characteristic of this order rather than being related to e.g., cold adaption.

Two cardiolipins based on a PGP polar group and generally termed BPGs (Corcelli, 2009; Angelini et al., 2012) were detected only in "Ca. Mh. thermophilum" HMET1 from the class Methanonatronarchaeia (Table 3). To the best of our knowledge BPGs have only been described to date in haloarchaea from the order Halobacteriales (Lattanzio et al., 2002; Corcelli, 2009; Angelini et al., 2012; Lobasso et al., 2015; Kellermann et al., 2016; although not in the Halobacteriales investigated in this study), but not before in any methanogenic members of the Euryarchaeota. Our results indicate that synthesis of BPGs is not restricted to the Halobacteriales. Indeed, Yoshinaga et al. (2012) detected novel lyso-cardiolipins (with only two isoprenoid chains) in surface sediments of methane-charged deep-ocean seeps which are usually dominated by uncultured anaerobic methanotrophic (ANMEs) archaea related to methanogenic euryarchaea, in particularly from the order Methanosarcinales (Knittel and Boetius, 2009). It is interesting to note that unlike the other 3 methanogens, and the majority of the other strains (cf. section Neutrophilic strains), "Ca. Mh. thermophilum” HMET1 


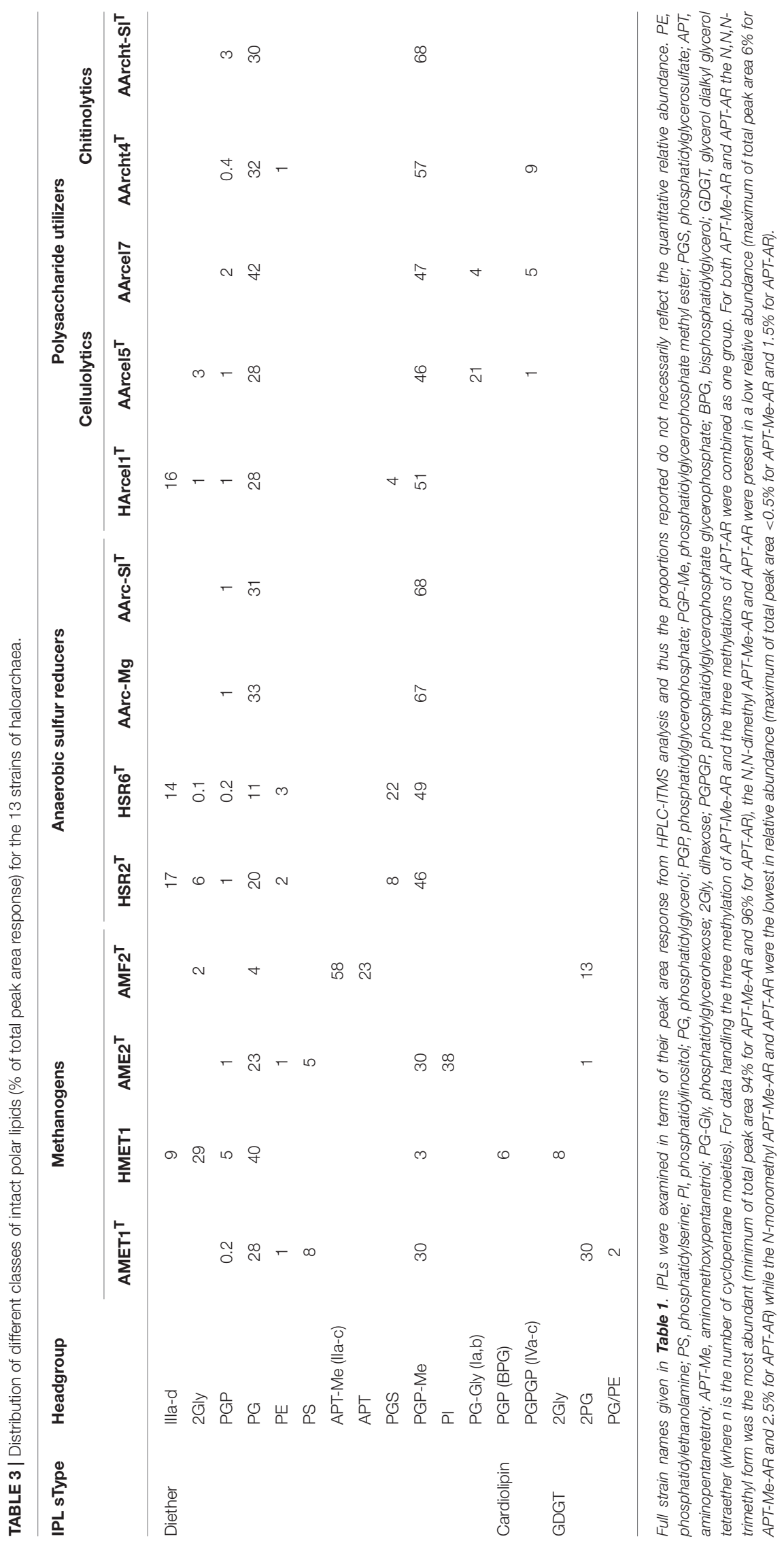




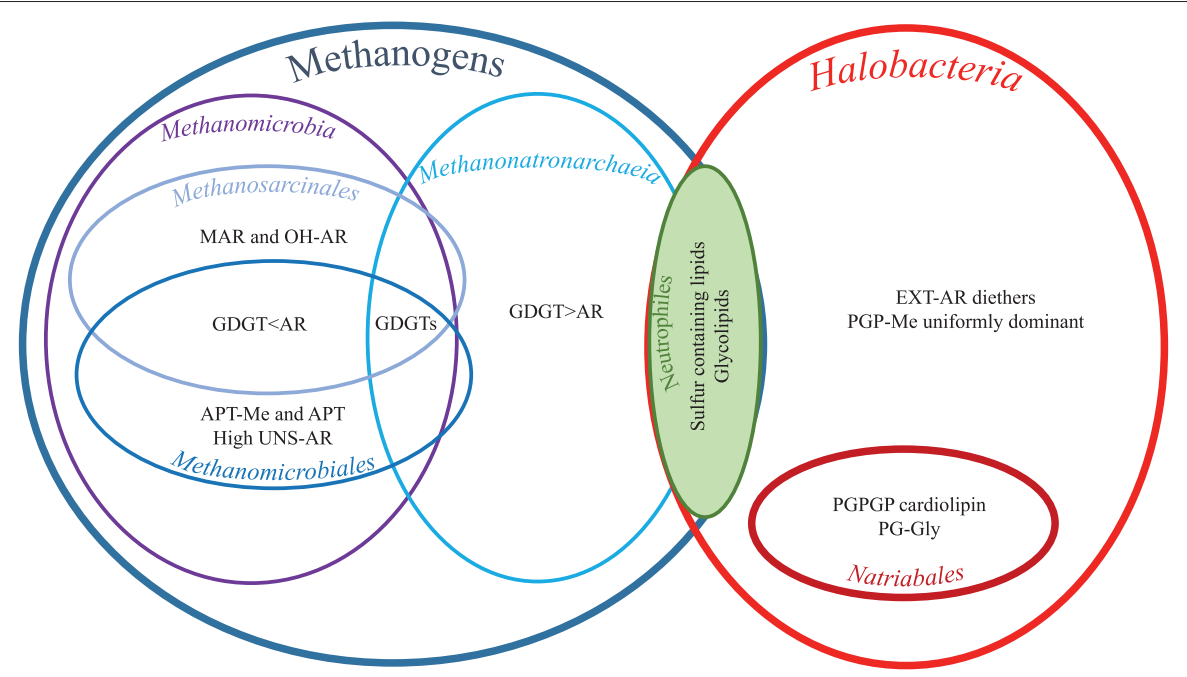

FIGURE 8 | Characteristic lipids as grouped by physiology, phylogenetic orders and classes. For full species names and for groups, orders, and classes see Table 1 For lipid abbreviations see text.

is a haloneutrophile, being cultured at $\mathrm{pH}$ 7. Previously, the haloneutrophile $H$. volcanii has been shown experimentally to adapt to low $\mathrm{Mg}^{2+}$ levels (as per the culturing conditions here, e.g., $1 \mathrm{mM} \mathrm{Mg}^{2+}$ ) by upregulating cardiolipin levels, in order to counterbalance the absence of "cardiolipin-surrogates" that form at higher $\mathrm{Mg}^{2+}$ concentrations, between the $\mathrm{Mg}^{2+}$ cations and two anionic PG lipids (Kellermann et al., 2016).

\section{Characteristic Lipids of the Halobacteria}

The absence of membrane-spanning GDGT lipids in Halobacteria has been hypothesized to have evolved to effectively respire using mechanisms acquired from bacteria through horizontal gene transfer (Kellermann et al., 2016). The authors suggest that the specific structure of haloarchaeal bilayer membranes has evolved to provide optimal balance between preventing ion permeability and maintaining sufficient fluidity for respiratory electron transport.

While diether lipids of the four methanogenic strains contained no EXT-AR (with the exception of an EXT-AR cardiolipin in ' $C a$. Mh. thermophilum' HMET1, see section Biosynthesis of EXT-AR), many of the analyzed Halobacteria strains showed a high proportion of EXT-AR in agreement with the other cultured genera from the class (Tindall et al., 1984; Teixidor et al., 1993; Tachibana, 1994; Xu et al., 1999, 2001; Gibson et al., 2005; Xue et al., 2005; Wang et al., 2007; Minegishi et al., 2010). This absence of diether EXT-AR in methanogens is in agreement with previous studies (e.g., Koga et al., 1998). HPLC-ITMS analysis (Table S1) revealed that the Halobacteria core lipids also contained Uns-EXT-AR. The presence of EXTAR has been suggested to provide a "zipper" like effect between the two layers of the membrane, interlinking the $\mathrm{C}_{25}$ isoprenoid of the "outward" facing lipid, with those of the "inward" facing lipids (De Rosa et al., 1982) providing increased membrane stability. Kellermann et al. (2016) hypothesized that in the case of alkaliphilic haloarchaea (six of the nine Halobacteria strains examined here) the EXT-AR zipper configuration within the bilayer is not compatible with membrane-shielding PG-cation interactions (as seen in neutrophilic haloarchaea). Therefore, alkaliphilic haloarchaea with high levels of EXT-AR would need to upregulate the amount of PGP-Me, to provide an alternative mode of $\mathrm{Mg}^{2+}$ buffering at the membrane surface. Indeed, in agreement with this idea, PGP-Me was the dominant headgroup (46-68\%, Table 3) across the Halobacteria and has been described previously as a distinguishing feature of haloarchaea (Kushwaha et al., 1981; Kates, 1992; Kates et al., 1993; Sprott et al., 1997; Lattanzio et al., 2002; Oren, 2002; Gibson et al., 2005; Tenchov et al., 2006; Xu et al., 2007; Angelini et al., 2012; Oger and Cario, 2013; Meador et al., 2014; Kellermann et al., 2016). During culturing experiments with neutrophilic $H$. volcanii, a correlation between the amount of PGP-Me and the $\mathrm{Mg}^{2+}$ concentration was observed (Kellermann et al., 2016) and was hypothesized to relate to the closely positioned, two negatively charged phosphate moieties which allow binding to divalent cation to reduce the permeability of monovalent cations under high salt concentrations [cf. Figure 9 of Kellermann et al. (2016)]. As stated above, six of the nine Halobacteria strains examined were haloalkaliphiles, while three were haloneutrophiles and all nine were cultured at very low $\mathrm{Mg}^{2+}$ concentrations ( $1 \mathrm{mM}$ ). Kellermann et al. (2016) suggested that in order to maintain membrane stability at low $\mathrm{Mg}^{2+}$ concentrations, haloneutrophiles adapt by upregulating cardiolipins in place of PG or PGP-Me, while haloalkaliphiles utilize the combined EXT-AR and PGP-Me approach described above. However, in our study we did not see a difference between the neutrophilic and alkaliphiles haloarchaea in terms of the relative amounts of cardiolipin, PG and PGP-Me or EXTAR. Therefore, it is the $\mathrm{Mg}^{2+}$ concentration which is more important in this case, rather than the $\mathrm{pH}$. It should be noted however that at high $\mathrm{pH}$ only low levels of $\mathrm{Mg}^{2+}$ remain in solution. 


\section{Characteristic Lipids of the Methanomicrobia}

While the two Methanonatronarchaeia and Mc. alkaliphilus $\mathrm{AMF}^{\mathrm{T}}$ all exhibited relatively common diether core lipid compositions (AR and Uns-AR), Ms. natronophilum $\mathrm{AME}^{\mathrm{T}}$ had the most complex diether lipid composition of any of the thirteen strains: based on GC-MS analysis (Table 2) it contained $45 \% \mathrm{AR}, 15 \% \mathrm{OH}-\mathrm{AR}$, and $6 \% \mathrm{MAR}$. The $16 \%$ of alkyl glycerol monoethers represents the Uns-AR and Uns-OHAR identified in intact form by LC-ITMS (Tables S1, S5). The presence of $\mathrm{OH}-\mathrm{AR}$ alongside $\mathrm{AR}$ is considered characteristic of the Methanosarcinales order to which Ms. natronophilum AME2 $^{\mathrm{T}}$ belongs (Koga et al., 1998). The hydroxylation of $\mathrm{AR}$ to produce $\mathrm{OH}-\mathrm{AR}$ has been postulated to have an effect on membrane stability, possibly increasing the polar surface area of the membrane or by creating hydrophilic pockets (Sprott et al., 1990). While MAR is not considered to be a general characteristic of the Methanosarcinales order, it has been previously reported in certain genera of the order, such as extremely halophilic Methanohalobium (Koga et al., 1998). The presence of MAR phospholipids has been shown to improve membrane impermeability to protons and solute leakage and membrane stability in methanogenic archaea (Koga et al., 1998) in a similar way to tetraether lipids. This structural effect is thought to explain its accumulation in the hyperthermophilic methanogen Methanococcus jannaschii [where it can account for up to $85 \%$ of the core lipids; (Sprott et al., 1991; Dannenmuller et al., 2000)], and other members of the Methanococcales order (Koga et al., 1998). The same might be true for extremely halophilic methanogens. As discussed above, Ms. natronophilum $\mathrm{AME}^{\mathrm{T}}$ is an extremely salt-tolerant alkaliphile (cultured at $3 \mathrm{M}$ total $\mathrm{Na}^{+}$) and the MAR and $\mathrm{OH}-\mathrm{AR}$ core lipid adaptions of this strain may be order- or species-specific adaptions to high salt and high $\mathrm{pH}$ conditions.

Two closely related polar headgroups (tri, di, and mono $\mathrm{N}$-methyl), APT and APT-Me were detected only in the single Methanomicrobiales member Mc. alkaliphilus $\mathrm{AMF}^{\mathrm{T}}$. While (tri, di- and mono) N-methyl APT-Me are all novel compounds, trimethyl APT has been described in a range of methanogenic euryarchaea, including the members of the order Methanomicrobiales, but, in agreement with our findings, not in the order Methanosarcinales (Ferrante et al., 1987; Koga et al., 1993, 1998; Koga and Morii, 2005). While APT has been considered previously a characteristic lipid headgroup of methanogenic archaea (Koga et al., 1993), our finding suggests it may be specific at the order level. It would be expected that the zwitterionic nature of these two headgroups would mean that they provide an overall neutral charge at the membrane surface and hence would not bind to cations in the same manner as negatively charged (anionic) lipids, e.g., PGP-Me (cf. section Characteristic lipids of the Halobacteria). This predominantly neutral membrane surface may have evolved to adapt to the conditions encountered by Mc. alkaliphilus $\mathrm{AMF}^{\mathrm{T}}$ of moderate salt (as per the culturing conditions $0.6 \mathrm{M} \mathrm{Na}^{+}$, $1 \mathrm{mM} \mathrm{Mg}^{2+}$ ) and high $\mathrm{pH}(9.5-10)$. It is of note that Szekely et al. (2011) found that, when modeling interactions between lipid membranes and various ions, while divalent ions do bind to zwitterionic headgroups, the presence of at least one double bond in the lipid tail is sufficient to prevent this divalent ion adsorption. The authors suggested that this was due to the looser packing of unsaturated lipids, allowing free rotation of the headgroup. It is of note therefore that Mc. alkaliphilus $\mathrm{AMF}^{\mathrm{T}}$, contained a high amount of unsaturated diether lipids of all 13 strains examined (12\% alkyl glycerol monoethers formed during acid hydrolysis from unsaturated diether lipids, Table 2). This suggests that the presence of high levels of zwitterionic headgroups and of unsaturated lipids in $\mathrm{AMF} 2^{\mathrm{T}}$ are interrelated membrane adaptions.

It should be noted that the other member of the Methanomicrobia class, Ms. natronophilum $\mathrm{AME}^{\mathrm{T}}$, also contained a high proportion of Uns-ARs (16\%, Table 2), whereas in all other classes it was $<5 \%$. Dawson et al. (2012) studied the effect of salinity on AR saturation in four strains of haloarchaea and found that the degree of unsaturation increased with increasing salinity of growth medium as well as with the strains' increasing salinity optimum. They hypothesized that increased AR unsaturation is a physiological adaptation to both maintain membrane fluidity and reduce ion-permeability as salinity increases. Kellermann et al. (2016) observed for H. volcanii an increase in the degree of unsaturation with increasing $\mathrm{Na}^{+}$levels primarily within the bulk IPL PG-AR (although they noted that total AR did not exhibit the same trend in unsaturation, which they suggested was due to impaired growth performance at both the low and high ends of the salt concentration range). However, a higher salt concentration does not explain the high level of AR unsaturation in the two Methanomicrobia as both Ms. natronophilum $\mathrm{AME}^{\mathrm{T}}$ and $M c$. alkaliphilus $\mathrm{AMF} 2^{\mathrm{T}}$ were cultured at the lowest salt concentrations of all 13 strains $\left(2 \mathrm{M}\right.$ and $0.6 \mathrm{M}$ total $\left.\mathrm{Na}^{+}\right)$. This suggests that AR unsaturation in response to salt concentrations is a class specific adaption, manifested at lower salt concentrations by these Methanomicrobia than the Methanonatronarchaeia and Halobacteria, which are all more extreme halophiles.

\section{Lipids of the Natrialbales}

A group of lipids only seen in members of the order Natrialbales included three PGPGP cardiolipins, one with two AR cores, one with an AR and an EXT-AR core and the final one with two EXT-AR cores (Table S1). These PGPGP cardiolipins were present in alkaliphilic polysaccharide utilizing haloarchaea "Na. chitinivorans" AArcht $4^{\mathrm{T}}, \mathrm{Nb}$. cellulositropha AArcel $5^{\mathrm{T}}$ and AArcel7, but not in the less alkaliphilic "Ha. desulfuricum" AArc-Sl ${ }^{\mathrm{T}}$. These PGPGP cardiolipins may be the same as unknown cardiolipins, postulated to be glycocardiolipins, detected previously in two species of alkaliphilic haloarchaea from the order Halobacteriales (Angelini et al., 2012). If this is the case then PGPGP cardiolipins may be characteristic of the alkaliphilic members of Halobacteria growing at low $\mathrm{Mg}$ background. It has been previously suggested, based on results from culturing experiments with the neutrophilic Halobacteriales member $H$. volcanii that at low $\mathrm{Mg}^{2+}$ concentration, the membrane upregulates the amount of PGP cardiolipin, to assure membrane integrity [cf. Figure 9 of Kellermann et al. (2016)]. At high $\mathrm{Mg}^{2+}$ levels, $H$. volcanii upregulated PGP-Me to increase 
$\mathrm{Mg}^{2+}$ binding at its closely positioned phosphate moieties (Kellermann et al., 2016). Thus, it may be possible that PGPGP headgroups could be orientated in a way that neighboring phosphate moieties are tethered via divalent cations, as per PGP-Me-AR, while also benefiting from the additional structural integrity of the cardiolipin structure.

The polar headgroup assigned as PG-Gly was only detected in two alkaliphilic Natrialbales ( $\mathrm{Nb}$. cellulositropha AArcel5 and AArcel7) but in no other orders. The PG-Gly headgroup with a diacyl core has been described in halophilic gammaproteobacteria of the genus Halomonas (Giordano et al., 2007), where it was postulated that the bulky headgroup would enhance steric protection through hydrogen bonding via glycosyl headgroups to ensure the osmotic stability of the cellular membrane under high-salt conditions. Furthermore, a very similar phosphoglycolipid with a sulfated sugar moiety was identified in alkaliphilic haloarchaeon N. moolapensis from the Halobacteriales order (Hoffmann et al., 2015). The presence of this headgroup in both extremely halophilic archaea and moderately halophilic bacteria further supports the hypothesis that this headgroup provides additional osmotic stability.

\section{Neutrophilic Strains}

Cellulolytic "Hc. cellulosivorans" HArcel $1^{\mathrm{T}}$ and sulfur-respiring Hd. formicicum HSR6 ${ }^{\mathrm{T}}$ and Hn. sulfurireducens HSR2 ${ }^{\mathrm{T}}$ of the order Halobacteriales all contained the PGS headgroup, not seen in any of the other 10 strains as well as the novel sulfur-containing headgroup (IIIa-d), which was also seen in methanogenic "Ca. Mh. thermophilum" HMET1. The presence of these sulfur containing lipids may be a distinctive characteristic associated with these Halobacteriales members or may relate to the neutrophilic nature of these extreme halophiles. Indeed, while nine strains out of 13 examined were alkaliphilic, the remaining four neutrophilic strains (cf. Table 1): methanogenic 'Ca. Mh. thermophilum' HMET1, sulfur-respiring $H d$. formicicum $\mathrm{HSR}^{\mathrm{T}}$ and $\mathrm{Hn}$. sulfurireducens $\mathrm{HSR} 2^{\mathrm{T}}$ and aerobic polysaccharide utilizing "Hc. cellulosivorans" HArcel1 ${ }^{\mathrm{T}}$ were all cultured at $\mathrm{pH} 7$. PGS was only detected in three of these strains (not in HMET1) and not in any of the alkaliphilic strains (Table 3). Indeed, PGS has been reported as a characteristic component in the other neutrophilic haloarchaea, such as the members of Haloferax and Halorubrum lacusprofundi from the Haloferacales (Kates, 1992; Gibson et al., 2005) and Halomicrobium mukohataei from the Halobacteriales (Oren et al., 2002).

Another characteristic of the neutrophilic strains was the presence of glycolipids. All four neutrophilic strains contained the 2Gly polar headgroup with an AR core, which was only detected in trace levels in two alkaliphiles, Mc. alkaliphilus $\mathrm{AMF}^{\mathrm{T}}$ and $\mathrm{Nb}$. cellulositropha AArcel5 $5^{\mathrm{T}}$ (Table 3). Similarly, the lipid composition of "Ca. Mh. thermophilum" HMET1 was dominated by 2 Gly-GDGT-0 whereas the three alkaliphilic methanogens only produced GDGTs with phospho-based polar headgroups (Tables 3, S1). This supports the assertion that glycolipids are absent or present only in trace amounts in membranes of alkaliphilic representatives of extremely halophilic Euryarchaeota (Oger and Cario, 2013; Siliakus et al., 2017).

\section{Biosynthesis of EXT-AR}

Low levels of an IPL cardiolipin with an EXT-AR core in 'Ca. Mh. thermophilum' HMET1 (Table S1; supported by the presence of EXT-AR in hydrolyzed core lipids, Table 2), is an interesting result as, of the 8 known orders of methanogens, only a representative of Methanomassiliicoccales has been described to date as containing EXT-AR (Koga and Morii, 2005; Becker et al., 2016). Indeed, the analyzed strains in the class Methanomicrobia (Ms. natronophilum $\mathrm{AME2}{ }^{\mathrm{T}}$ and $\mathrm{Mc}$. alkaliphilus $\mathrm{AMF} 2^{\mathrm{T}}$ ) did not contain any EXT-AR, whereas all analyzed Halobacteria did (cf. Tables 2, S5). These results led us to the hypothesis that the close relationship between the novel class-level lineage Methanonatronarchaeia and the class Halobacteria (Sorokin et al., 2017a, cf. Figure 1) means that they share the same genetic capability to produce EXT-AR. It should be noted, however, that EXT-AR was only present in low levels in "Ca. Mh. thermophilum" HMET1 (Tables 2, S1) and that $M n$. thermophilum $\mathrm{AMET}^{\mathrm{T}}$, also a member of the Methanonatronarchaeia, did not contain any EXT-AR. It is possible that the presence of EXT-AR in HMET1 and not $A M E T 1^{\mathrm{T}}$ is related to culture conditions as the medium for HMET1 contained $4 \mathrm{M} \mathrm{NaCl}$, while that of $\mathrm{AMET}^{\mathrm{T}}$ contained $2 \mathrm{M} \mathrm{Na}^{+}$as $\mathrm{NaCl}$ and $2 \mathrm{M} \mathrm{Na}^{+}$as carbonates. Hence the osmotic pressure in case of $\mathrm{AMET1}^{\mathrm{T}}$ was much lower, since sodium carbonates, as weak electrolytes, impose roughly two time less osmotic pressure than the strongly electrolytic $\mathrm{NaCl}$ (Robinson and Macaskill, 1979). Dawson et al. (2012) noted previously that, while the presence of EXT-AR seems to be in part taxonomic, an increase in its abundance is advantageous for haloarchaea as it decreases membrane ion-permeability. As described above, the presence of EXT-AR has been suggested to provide a "zipper" like effect between the two layers of the membrane providing increased membrane stability (De Rosa et al., 1982). It has also been found that $\mathrm{C}_{25}-\mathrm{C}_{25}$ EXT-AR liposomes are thicker than $\mathrm{C}_{20}-\mathrm{C}_{20}$ AR liposomes and have relatively lower permeability (Gmajner et al., 2011), so a similar effect could be expected of the $\mathrm{C}_{20}-\mathrm{C}_{25}$ EXT-AR detected in this study.

In order to examine the genetic capability to produce EXT-AR we examined the polyprenyl synthases (belonging to the prenyltransferase family) involved in the elongation of isoprenoids (Liang et al., 2002) in the genomes of the two members of Methanonatronarchaeia class along with eight haloarchaeal isolates from this study plus additional archaeal species, including a single-cell genome sequence, from Nereus Deep in the Red Sea, belonging to a putatively novel family within the archaeal candidate division SA1 (Ngugi and Stingl, 2018), to which the two members of Methanonatronarchaeia also belong (Figure 9). Homology search analysis revealed multiple putative polyprenyl synthases in the analyzed genomes. Specific amino acid (AA) residues of the polyprenyl synthase genes are known to determine the length of the isoprenoid chain. Specifically, the fifth amino acid before the First Aspartate-Rich Motif (FARM) has been found to determine the length of the formed isoprenoid chain. For the case of the $\mathrm{C}_{25}$ isoprenoid chains of the EXT$\mathrm{AR}$, also the eighth and 11th amino acids are important in the determination of the $\mathrm{C}_{25}$ extension (Liang et al., 2002). Figure 9 illustrates the relationships between the different polyprenyl 


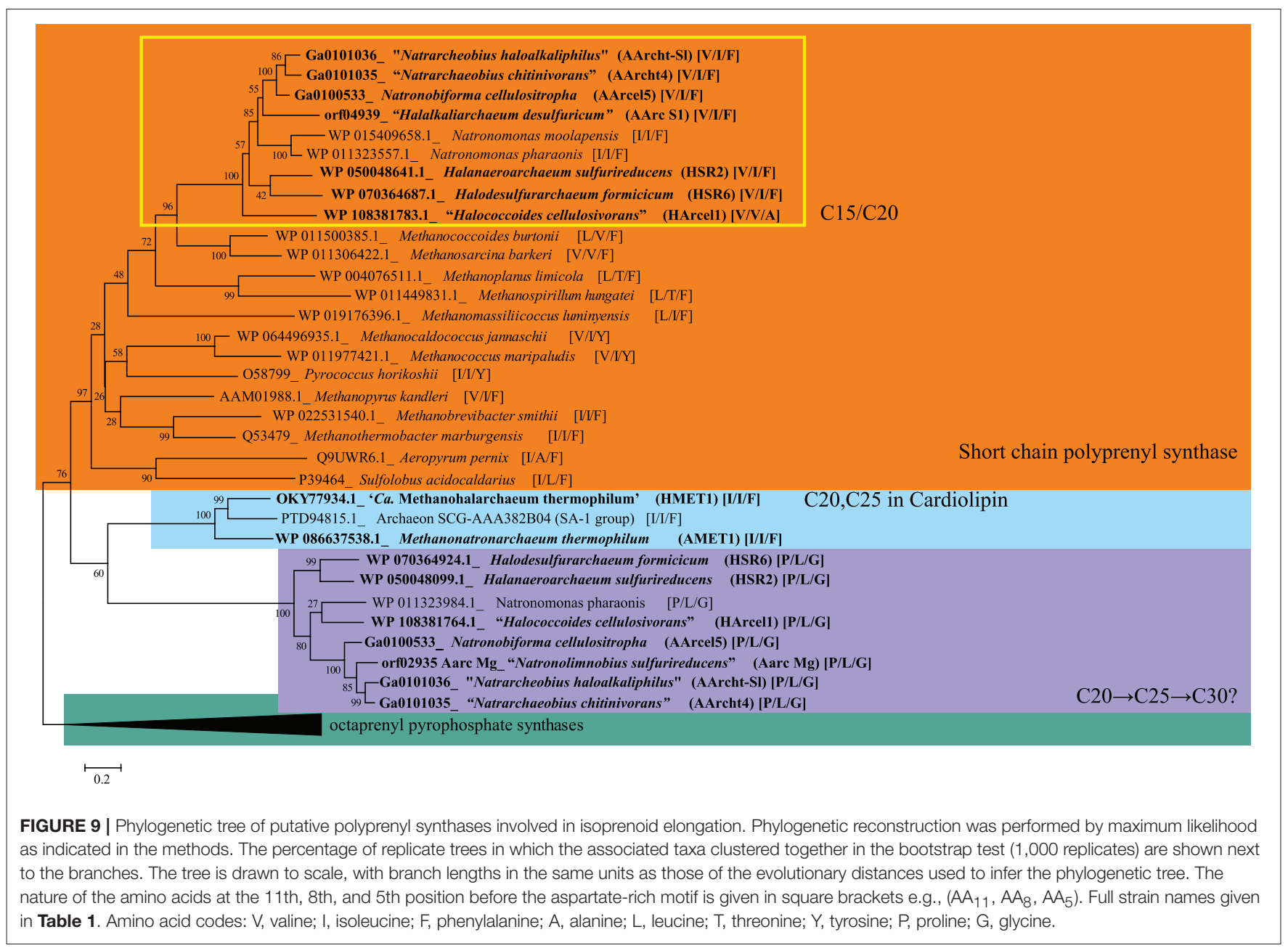

synthases present in the archaeal genomes examined and the nature of the amino acids at the 11th, 8th, and 5th position before the aspartate-rich motif (given in square brackets e.g., $\left.\left[\mathrm{AA}_{11}, \mathrm{AA}_{8}, \mathrm{AA}_{5}\right]\right)$. Bulky amino acids such as phenylalanine $(\mathrm{F})$ block the length of the isoprenoids at $\mathrm{C}_{20}$, while smaller amino acids such as serine (S) allow for elongation to $\mathrm{C}_{25}$ and beyond (Ohnuma et al., 1996; Liang et al., 2002).

Many of the examined archaeal genomes encode multiple putative polyprenyl synthases, generally separated in function by the nature of the specific FARM amino acids described above (Figure 9). A major cluster of synthases, which we assigned as long chain polyprenyl synthases (Figure 9), are all characterized by a $\mathrm{P} / \mathrm{L} / \mathrm{G}$ (proline 11 , leucine 8 , glycine ${ }_{5}$ ) FARM motif. Indeed, replacement of bulky $\mathrm{F}$ at the fifth position with a smaller amino acid residue such as serine ( $\mathrm{S}$ ) has been described as the most effective way to elongate beyond a $\mathrm{C}_{20}$ chain (Ohnuma et al., 1996; Liang et al., 2002). A similar effect would be expected from $\mathrm{G}$ at the fifth position, as it is smaller still than serine. The second major cluster, which we assigned as short chain polyprenyl synthases, was characterized by the presence of motives with the bulky, chain-limiting $\mathrm{F}$ at the fifth position. It should be noted here that the polyprenyl synthases clustering does not reflect a dichotomy between species that have been shown to produce or not produce EXT-AR. Indeed, many species contain both the short and long chain polyprenyl synthases, as would be expected as they produce a range of isoprenoid-based products with varying chain lengths. Another point to note is that A. pernix is known to produce exclusively a $\mathrm{C}_{25}, \mathrm{C}_{25} \mathrm{AR}$ (Morii et al., 1999). However, it only contained one putative polyprenyl synthase, which clustered with the short chain polyprenyl synthases (Figure 9), most closely with acidophilic $S$. acidocaldarius which does not produce EXT-AR (Sprott et al., 1997). In this case it is important to note that it is the FARM motif of A. pernix I/A/F (isoleucine ${ }_{11}$, alanine $8, F_{5}$ ) that distinguishes the enzymes' ability to form extended isoprenoids beyond the $\mathrm{C}_{20}$ length. Indeed, in the case of A. pernix it is the presence of the relatively small and compact $\mathrm{A}$ at the eighth position which potentially determines the $\mathrm{C}_{25}$ chain length of the product (Liang et al., 2002). Conversely, S. acidocaldarius contains the bulkier L in the eighth position. The clustering of these genes together, despite this difference, suggests that the polyprenyl synthase of A. pernix was originally a short chain polyprenyl synthase which underwent certain amino acid replacements, but overall remains most closely related to the other short chain polyprenyl synthases. Interestingly, although the methanogen Methanomassiliicoccus luminyensis has been described as containing EXT-AR (Becker 
et al., 2016), based on its very bulky, chain-limiting FARM motif $\left(\mathrm{L}_{11}, \mathrm{I}_{8}, \mathrm{~F}_{5}\right)$ as pointed out in Figure 9, this would not be expected.

A third cluster of polyprenyl synthases contained the three members of the archaeal candidate division SA1: the only two members of Methanonatronarchaeia presently known in culture, "Ca. Mh. thermophilum" HMET1 and Mn. thermophilum $\mathrm{AMET}^{\mathrm{T}}$ and a single-cell genome sequence from Nereus Deep in the Red Sea. All three only contained one putative polyprenyl synthase with two Is, and the relatively bulky $\mathrm{F}$ at the 11th, 8th, and 5 th positions, a motif associated with short chain polyprenyl synthase. However, these putative polyprenyl synthases cluster far apart from all the other short chain polyprenyl synthases and cluster closer to the long chain polyprenyl synthases (Figure 9). While this conflicting motif and clustering provide no specific evidence that this is the gene involved in the production of EXTAR containing cardiolipins in Methanonatronarchaeia, it does raise the possibility that these novel extremophilic methanogens utilize a different isoprenoid elongation mechanism than the other extremely halophilic euryarchaea examined here. Perhaps their isolated phylogenetic position has afforded them alternative pathways to adapt their membranes to hypersaline conditions using EXT-AR. However, as EXT-AR was only present in low levels in ' $\mathrm{Ca}$. Mh. thermophilum' HMET1 (Tables 2, S1) and was not present in $M n$. thermophilum $\mathrm{AMET}^{\mathrm{T}}$, it does not appear to be a significant membrane adaptation under the culturing conditions examined in this study.

\section{CONCLUSIONS}

Analyzing a large set of novel halo(alkali)philic representatives of Euryarchaeota, novel diether-based lipids were detected including a PG-Gly headgroup combined with a diether core, an APT-like lipid with an additional methoxy group in place of a hydroxy group on the pentanetetrol and finally headgroups with elemental composition of either $\mathrm{C}_{12} \mathrm{H}_{25} \mathrm{NO}_{13} \mathrm{~S}$ or $\mathrm{C}_{12} \mathrm{H}_{25} \mathrm{NO}_{16} \mathrm{~S}_{2}$. Furthermore, novel cardiolipins were detected in three strains: a putative PGPGP polar group bridging the diether components. The presence of cardiolipins with EXTAR in one of the Methanonatronarchaeia strains was unusual, as only one other methanogenic archaeal order has been reported to produce EXT-AR. Both Methanonatronarchaeia strains contain a specific polyprenyl synthase which clustered separately from those of the haloarchaea. This may indicate the potential of these strains to synthesize EXT-AR.

We compared the distribution of membrane lipids across the 13 strains to examine what factors determined lipid composition, including the phylogenetic relationships between the strains, the three different metabolic processes they carryout and adaptions associated with the $\mathrm{pH}$. In general we found that the lipid distribution of the 13 strains could be generally separated into two, the methanogens (group) and the Halobacteria (class) based on the presence of specific core lipids. Within the methanogen group adaption to high or more moderate salt concentration resulted in the extremely halophilic class Methanonatronarchaeia containing more GDGTs than AR, while the less halophilic members of the class Methanomicrobia contained more AR than GDGTs. The methanogen Ms. natronophilum AME2 ${ }^{\mathrm{T}}$ had the most complex diether lipid composition of any of the 13 strains, including $\mathrm{OH}-\mathrm{AR}$ and MAR which we surmise is an order-specific membrane adaption. The zwitterionic lipids APT and APT-Me headgroups were detected only in the Methanomicrobiales member Mc. alkaliphilus $\mathrm{AMF}^{\mathrm{T}}$, which also contained the highest proportion of unsaturated lipids. Many of the Halobacteria strains contained a high proportion of the EXT-AR core and PGP-Me headgroup in agreement with the other cultured genera from the class. Within the Halobacteria only alkaliphilic members of the Natrialbales order contained PGPGP cardiolipins and the PG-Gly headgroup. The four neutrophilic strains belonging to Haloferacales and Halobacteriales orders were characterized by the presence of sulfur-containing headgroups and glycolipids.

\section{DATA AVAILABILITY}

All datasets generated for this study are included in the manuscript and/or the supplementary files.

\section{AUTHOR CONTRIBUTIONS}

NB carried out data analysis and wrote manuscript. DS isolated and cultured archaea. EH oversaw analytical methods and carried out data analysis. MK and WR carried out extractions and data analysis. LV carried out homology search and phylogenetic analyses. HW carried out NMR analysis and JS conceived and supervised the project.

\section{FUNDING}

This project received funding from the European Research Council (ERC) under the European Union's Horizon 2020 research and innovation programme (grant agreement No 694569) and NWO Groot (grant number 175.107.301.10). DS was supported by the Russian Foundation for Basic Research (RFBR grant 19-04-00401) and in part by the Russian Ministry of Science and Higher Education. DS and JS were also supported by the GravitationSIAM Program of the Dutch Ministry of Education and Science (grant 24002002).

\section{ACKNOWLEDGMENTS}

We thank Diana Sahonero, Stefan Schouten, Helge Niemann, and Jan de Leeuw for useful discussions during the preparation of this manuscript. We are also very grateful to both the reviewers for suggesting constructive edits that improved the manuscript significantly.

\section{SUPPLEMENTARY MATERIAL}

The Supplementary Material for this article can be found online at: https://www.frontiersin.org/articles/10.3389/fmicb. 2019.00377/full\#supplementary-material 


\section{REFERENCES}

Amoozegar, M. A., Siroosi, M., Atashgahi, S., Smidt, H., and Ventosa, A. (2017). Systematics of haloarchaea and biotechnological potential of their hydrolytic enzymes. Microbiology 163, 623-645. doi: 10.1099/mic.0.000463

Andrei, A.-S., Banciu, H. L., and Oren, A. (2012). Living with salt: metabolic and phylogenetic diversity of archaea inhabiting saline ecosystems. FEMS Microbiol. Lett. 330, 1-9. doi: 10.1111/j.1574-6968.2012.02526.x

Angelini, R., Corral, P., Lopalco, P., Ventosa, A., and Corcelli, A. (2012). Novel ether lipid cardiolipins in archaeal membranes of extreme haloalkaliphiles. Biochim. Biophys. Acta 1818, 1365-1373. doi: 10.1016/j.bbamem.2012. 02.014

Becker, K. W., Elling, F. J., Yoshinaga, M. Y., Söllinger, A., Urich, T., and Hinrichs, K.-U. (2016). Unusual butane- and pentanetriol-based tetraether lipids in Methanomassiliicoccus luminyensis, a representative of the seventh order of methanogens. Appl. Environ. Microbiol. 82, 4505-4516. doi: 10.1128/AEM.00772-16

Begemann, M. B., Mormile, M. R., Paul, V. G., and Vidt, D. J. (2011). "Potential enhancement of biofuel production through enzymatic biomass degradation activity and biodiesel production by halophilic microorganisms," in Halophiles and Hypersaline Environments: Current Research and Future Trends, eds. A. Ventosa, A. Oren, and Y. Ma (Berlin; Heidelberg: Springer Berlin Heidelberg), 341-357. doi: 10.1007/978-3-642-20198-1_18

Besseling, M. A., Hopmans, E. C., Boschman, R. C., Damsté, S., S, J., and Villanueva, L. (2018). Benthic archaea as potential sources of tetraether membrane lipids in sediments across an oxygen minimum zone. Biogeosciences 15, 4047-4064. doi: 10.5194/bg-15-4047-2018

Corcelli, A. (2009). The cardiolipin analogues of Archaea. Biochim. Biophys. Acta 1788, 2101-2106. doi: 10.1016/j.bbamem.2009.05.010

Corcelli, A., Colella, M., Mascolo, G., Fanizzi, F. P., and Kates, M. (2000). A novel glycolipid and phospholipid in the purple membrane. Biochemistry 39, 3318-3326. doi: 10.1021/bi992462z

Dannenmuller, O., Arakawa, K., Eguchi, T., Kakinuma, K., Blanc, S., Albrecht, A.-M., et al. (2000). Membrane properties of archæal macrocyclic diether phospholipids. Chemistry 6, 645-654. doi: 10.1002/(SICI)15213765(20000218)6:4<645::AID-CHEM645>3.0.CO;2-A;2-A

Dawson, K. S., Freeman, K. H., and Macalady, J. L. (2012). Molecular characterization of core lipids from halophilic archaea grown under different salinity conditions. Org. Geochem. 48, 1-8. doi: 10.1016/j.orggeochem.2012.04.003

De Rosa, M., Gambacorta, A., Nicolaus, B., Ross, H. N. M., Grant, W. D., and Bu'Lock, J. D. (1982). An asymmetric archaebacterial diether lipid from alkaliphilic halophiles. Microbiology 128, 343-348. doi: 10.1099/00221287-128-2-343

de Souza, L. M., Müller-Santos, M., Iacomini, M., Gorin, P. A. J., and Sassaki, G. L. (2009). Positive and negative tandem mass spectrometric fingerprints of lipids from the halophilic Archaea Haloarcula marismortui. J. Lipid Res. 50, 1363-1373. doi: 10.1194/jlr.M800478-JLR200

Edgar, R. C. (2004). MUSCLE: multiple sequence alignment with high accuracy and high throughput. Nucleic Acids Res. 32, 1792-1797. doi: $10.1093 / \mathrm{nar} / \mathrm{gkh} 340$

Elling, F. J., Könneke, M., Mußmann, M., Greve, A., and Hinrichs, K.-U. (2015). Influence of temperature, $\mathrm{pH}$, and salinity on membrane lipid composition and TEX86 of marine planktonic thaumarchaeal isolates. Geochim. Cosmochim. Acta 171, 238-255. doi: 10.1016/j.gca.2015.09.004

Ferrante, G., Ekiel, I., and Sprott, G. D. (1987). Structures of diether lipids of Methanospirillum hungatei containing novel head groups $N, N$-diniethylaminoand N,N,N-trimethylaminopentanetetrol. Biochim. Biophys. Acta 921, 281-291. doi: 10.1016/0005-2760(87)90029-4

Gibson, J. A. E., Miller, M. R., Davies, N. W., Neill, G. P., Nichols, D. S., and Volkman, J. K. (2005). Unsaturated diether lipids in the psychrotrophic archaeon Halorubrum lacusprofundi. Syst. Appl. Microbiol. 28, 19-26. doi: 10.1016/j.syapm.2004.09.004

Gibson, R. A., van der Meer, M. T. J., Hopmans, E. C., Reysenbach, A.-L., Schouten, S., and Sinninghe Damsté, J. S. (2013). Comparison of intact polar lipid with microbial community composition of vent deposits of the Rainbow and Lucky Strike hydrothermal fields. Geobiology 11, 72-85. doi: 10.1111/gbi.12017
Giordano, A., Vella, F. M., Romano, I., and Gambacorta, A. (2007). Structural elucidation of a novel phosphoglycolipid isolated from six species of Halomonas. J. Lipid Res. 48, 1825-1831. doi: 10.1194/jlr.M700152-JLR200

Gmajner, D., Ota, A., Šentjurc, M., and Ulrih, N. P. (2011). Stability of diether C25,25 liposomes from the hyperthermophilic archaeon Aeropyrum pernix K1. Chem. Phys. Lipids 164, 236-245. doi: 10.1016/j.chemphyslip.2011.01.005

Hoffmann, A., Kovermann, M., Oberwinkler, T., Siedler, F., Cortina, N. S., Balbach, J., et al. (2015). Novel sulfated phosphoglycolipids from Natronomonas moolapensis. Chem. Phys. Lipids 191, 8-15. doi: 10.1016/j.chemphyslip.2015.06.004

Hopmans, E. C., Schouten, S., Pancost, R. D., van der Meer, M. T., and Sinninghe Damsté, J. S. (2000). Analysis of intact tetraether lipids in archaeal cell material and sediments by high performance liquid chromatography/atmospheric pressure chemical ionization mass spectrometry. Rapid Commun. Mass Spectrom. 14, 585-589. doi: 10.1002/(SICI)10970231(20000415)14:7<585::AID-RCM913>3.0.CO;2-N

Jones, D. T., Taylor, W. R., and Thornton, J. M. (1992). The rapid generation of mutation data matrices from protein sequences. Comput. Appl. Biosci. $8,275-282$.

Jukes, T. H., and Cantor, C. R. (1969). "Evolution of protein molecules", in Mammalian Protein Metabolism, III. eds H. N. Munro (New York, NY: Academic Press), 21-132.

Kates, M. (1992). "Archaebacterial lipids: structure, biosynthesis and function," in The Archaebacteria: Biochemistry and Biotechnology, eds. M. J. Danson, D. W. Hough, and G. G. Lunt (London: Portland Press), 51-72.

Kates, M., Moldoveanu, N., and Stewart, L. C. (1993). On the revised structure of the major phospholipid of Halobacterium salinarium. Biochim. Biophys. Acta $1169,46-53$.

Kellermann, M. Y., Yoshinaga, M. Y., Valentine, R. C., Wörmer, L., and Valentine, D. L. (2016). Important roles for membrane lipids in haloarchaeal bioenergetics. Biochim. Biophys. Acta 1858, 2940-2956. doi: 10.1016/j.bbamem.2016.08.010

Knittel, K., and Boetius, A. (2009). Anaerobic oxidation of methane: progress with an unknown process. Annu. Rev. Microbiol. 63, 311-334. doi: 10.1146/annurev.micro.61.080706.093130

Koga, Y., and Morii, H. (2005). Recent advances in structural research on ether lipids from archaea including comparative and physiological aspects. Biosci. Biotechnol. Biochem. 69, 2019-2034. doi: 10.1271/bbb.69.2019

Koga, Y., Morii, H., Akagawa-Matsushita, M., and Ohga, M. (1998). Correlation of polar lipid composition with $16 \mathrm{~S}$ rRNA phylogeny in methanogens. Further Analysis of Lipid Component Parts. Biosci. Biotechnol. Biochem. 62, 230-236. doi: $10.1271 / \mathrm{bbb} .62 .230$

Koga, Y., and Nakano, M. (2008). A dendrogram of archaea based on lipid component parts composition and its relationship to rRNA phylogeny. Syst. Appl. Microbiol. 31, 169-182. doi: 10.1016/j.syapm.2008. 02.005

Koga, Y., Nishihara, M., Morii, H., and Akagawa-Matsushita, M. (1993). Ether polar lipids of methanogenic bacteria: structures, comparative aspects, and biosyntheses. Microbiol. Rev. 57, 164-182.

Kushwaha, S. C., Kates, M., Sprott, G. D., and Smith, I. C. (1981). Novel complex polar lipids from the methanogenic archaebacterium Methanospirillum hungatei. Science 211, 1163-1164. doi: 10.1126/science.7466385

Kushwaha, S. C., Kramer, J. K. G., and Kates, M. (1975). Isolation and characterization of C50-carotenoid pigments and other polar isoprenoids from Halobacterium cutirubrum. Biochim. Biophys. Acta 398, 303-314. doi: 10.1016/0005-2760(75)90146-0

Lattanzio, V. M., Corcelli, A., Mascolo, G., and Oren, A. (2002). Presence of two novel cardiolipins in the halophilic archaeal community in the crystallizer brines from the salterns of Margherita di Savoia (Italy) and Eilat (Israel). Extremophiles 6, 437-444. doi: 10.1007/s00792-0020279-2

Liang, P.-H., Ko, T.-P., and Wang, A. H.-J. (2002). Structure, mechanism and function of prenyltransferases. Eur. J. Biochem. 269, 3339-3354. doi: 10.1046/j.1432-1033.2002.03014.x

Lipp, J. S., and Hinrichs, K.-U. (2009). Structural diversity and fate of intact polar lipids in marine sediments. Geochim. Cosmochim. Acta 73, 6816-6833. doi: 10.1016/j.gca.2009.08.003 
Lipp, J. S., Morono, Y., Inagaki, F., and Hinrichs, K.-U. (2008). Significant contribution of Archaea to extant biomass in marine subsurface sediments. Nature 454, 991-994. doi: 10.1038/nature07174

Liu, X.-L., Leider, A., Gillespie, A., Gröger, J., Versteegh, G. J. M., and Hinrichs, K.U. (2010). Identification of polar lipid precursors of the ubiquitous branched GDGT orphan lipids in a peat bog in Northern Germany. Org. Geochem. 41, 653-660. doi: 10.1016/j.orggeochem.2010.04.004

Lobasso, S., Pérez-Davó, A., Vitale, R., Sánchez, M. M.-, and Corcelli, A. (2015). Deciphering archaeal glycolipids of an extremely halophilic archaeon of the genus Halobellus by MALDI-TOF/MS. Chem. Phys. Lipids 186, 1-8. doi: 10.1016/j.chemphyslip.2014.11.002

Mathai, J. C., Sprott, G. D., and Zeidel, M. L. (2001). Molecular mechanisms of water and solute transport across archaebacterial lipid membranes. J. Biol. Chem. 276, 27266-27271. doi: 10.1074/jbc.M103265200

Meador, T. B., Gagen, E. J., Loscar, M. E., Goldhammer, T., Yoshinaga, M. Y., Wendt, J., et al. (2014). Thermococcus kodakarensis modulates its polar membrane lipids and elemental composition according to growth stage and phosphate availability. Front. Microbiol. 5:10. doi: 10.3389/fmicb.2014. 00010

Minegishi, H., Echigo, A., Nagaoka, S., Kamekura, M., and Usami, R. (2010). Halarchaeum acidiphilum gen. nov., sp. nov., a moderately acidophilic haloarchaeon isolated from commercial solar salt. Int. J. Syst. Evol. Microbiol. 60, 2513-2516. doi: 10.1099/ijs.0.013722-0

Morii, H., Yagi, H., Akutsu, H., Nomura, N., Sako, Y., and Koga, Y. (1999). A novel phosphoglycolipid archaetidyl(glucosyl)inositol with two sesterterpanyl chains from the aerobic hyperthermophilic archaeon Aeropyrum pernix K1. Biochim. Biophys. Acta 1436, 426-436.

Ngugi, D. K., and Stingl, U. (2018). High-quality draft single-cell genome sequence belonging to the archaeal candidate division SAl, isolated from nereus deep in the Red Sea. Genome Announc. 6, e00383-e00318. doi: 10.1128/genomeA.00383-18

Nichols, D. S., Miller, M. R., Davies, N. W., Goodchild, A., Raftery, M., and Cavicchioli, R. (2004). Cold adaptation in the Antarctic Archaeon Methanococcoides burtonii involves membrane lipid unsaturation. J. Bacteriol. 186, 8508-8515. doi: 10.1128/JB.186.24.8508-8515.2004

Nishihara, M., and Koga, Y. (1991). Hydroxyarchaetidylserine and hydroxyarchaetidyl-myo-inositol in Methanosarcina barkeri: polar lipids with a new ether core portion. Biochim. Biophys. Acta 1082, 211-217

Oger, P. M., and Cario, A. (2013). Adaptation of the membrane in Archaea. Biophys. Chem. 183, 42-56. doi: 10.1016/j.bpc.2013.06.020

Ohnuma, S., Hirooka, K., Hemmi, H., Ishida, C., Ohto, C., and Nishino, T. (1996). Conversion of product specificity of Archaebacterial Geranylgeranyldiphosphate Synthase Identification of essential amino acid residues for chain length determination of prenyltransferase reaction. J. Biol. Chem. 271, 18831-18837. doi: 10.1074/jbc.271.31.18831

Oren, A. (1999). Bioenergetic aspects of halophilism. Microbiol. Mol. Biol. Rev. $63,334-348$

Oren, A. (2002). Molecular ecology of extremely halophilic Archaea and Bacteria. FEMS Microbiol. Ecol. 39, 1-7. doi: 10.1111/j.1574-6941.2002.tb00900.x

Oren, A., Elevi, R., Watanabe, S., Ihara, K., and Corcelli, A. (2002). Halomicrobium mukohataei gen. nov., comb. nov., and emended description of Halomicrobium mukohataei. Int. J. Syst. Evol. Microbiol. 52, 1831-1835. doi: 10.1099/00207713-52-5-1831

Pancost, R. D., Bouloubassi, I., Aloisi, G., Sinninghe Damsté, J. S., and Scientific, Party, the M. S. (2001). Three series of non-isoprenoidal dialkyl glycerol diethers in cold-seep carbonate crusts. Org. Geochem. 32, 695-707. doi: 10.1016/S0146-6380(01)00015-8

Pitcher, A., Hopmans, E. C., Mosier, A. C., Park, S.-J., Rhee, S.-K., Francis, C. A., et al. (2011). Core and intact polar glycerol dibiphytanyl glycerol tetraether lipids of ammonia-oxidizing archaea enriched from marine and estuarine sediments. Appl. Environ. Microbiol. 77, 3468-3477. doi: 10.1128/AEM.02758-10

Robinson, R. A., and Macaskill, J. B. (1979). Osmotic coefficients of aqueous sodium carbonate solutions at $25^{\circ} \mathrm{C}$. J. Solution Chem. 8, 35-40. doi: $10.1007 /$ BF00646807

Rossel Cartes, P. (2009). Microbial Communities Performing Anaerobic Oxidation of Methane: Diversity of Lipid Signatures and Habitats. University of Bremen.
Rossel, P., Lipp, J., Fredricks, H., Arnds, J., Boetius, A., Elvert, M., et al. (2008) Intact polar lipids of anaerobic methanotrophic Archaea and associated bacteria. Org. Geochem. 39, 992-999. doi: 10.1016/j.orggeochem.2008. 02.021

Rossel, P. E., Elvert, M., Ramette, A., Boetius, A., and Hinrichs, K.-U. (2011). Factors controlling the distribution of anaerobic methanotrophic communities in marine environments: evidence from intact polar membrane lipids. Geochim. Cosmochim. Acta 75, 164-184. doi: 10.1016/j.gca.2010. 09.031

Saitou, N., and Nei, M. (1987). The neighbor-joining method: a new method for reconstructing phylogenetic trees. Mol. Biol. Evol. 4, 406-425. doi: 10.1093/oxfordjournals.molbev.a040454

Schouten, S., Hopmans, E. C., Baas, M., Boumann, H., Standfest, S., Koenneke, M., et al. (2008). Intact membrane lipids of "Candidatus Nitrosopumilus maritimus," a cultivated representative of the cosmopolitan mesophilic group I crenarchaeota. Appl. Environ. Microbiol. 74, 2433-2440. doi: 10.1128/AEM.01709-07

Schouten, S., Hopmans, E. C., and Sinninghe Damsté, J. S. (2013). The organic geochemistry of glycerol dialkyl glycerol tetraether lipids: a review. Org. Geochem. 54, 19-61. doi: 10.1016/j.orggeochem.2012.09.006

Schubotz, F., Wakeham, S. G., Lipp, J. S., Fredricks, H. F., and Hinrichs, K.-U. (2009). Detection of microbial biomass by intact polar membrane lipid analysis in the water column and surface sediments of the Black Sea. Environ. Microbiol. 11, 2720-2734. doi: 10.1111/j.1462-2920.2009.0 1999. $\mathrm{x}$

Shinoda, W., Shinoda, K., Baba, T., and Mikami, M. (2005). Molecular dynamics study of bipolar tetraether lipid membranes. Biophys. J. 89, 3195-3202. doi: 10.1529/biophysj.105.060962

Siliakus, M. F., van der Oost, J., and Kengen, S. W. M. (2017). Adaptations of archaeal and bacterial membranes to variations in temperature, $\mathrm{pH}$ and pressure. Extremophiles 21, 651-670. doi: 10.1007/s00792-0170939-x

Sinninghe Damsté, J. S., Rijpstra, W. I. C., Hopmans, E. C., Weijers, J. W. H., Foesel, B. U., Overmann, J., et al. (2011). 13,16-Dimethyl Octacosanedioic Acid (iso-Diabolic Acid), a common membrane-spanning lipid of acidobacteria subdivisions 1 and 3. Appl. Environ. Microbiol. 77, 4147-4154. doi: 10.1128/AEM.00466-11

Sinninghe Damsté, J. S., Schouten, S., Hopmans, E. C., van Duin, A. C T., and Geenevasen, J. A. J. (2002). Crenarchaeol: the characteristic core glycerol dibiphytanyl glycerol tetraether membrane lipid of cosmopolitan pelagic crenarchaeota. J. Lipid Res. 43, 1641-1651. doi: 10.1194/jlr.M200148JLR200

Sorokin, D. Y., Abbas, B., Geleijnse, M., Pimenov, N. V., Sukhacheva, M. V., and van Loosdrecht, M. C. M. (2015a). Methanogenesis at extremely haloalkaline conditions in the soda lakes of Kulunda Steppe (Altai, Russia). FEMS Microbiol. Ecol. 91:fiv016. doi: 10.1093/femsec/fiv016

Sorokin, D. Y., Abbas, B., Merkel, A. Y., Rijpstra, W. I. C., Damsté, J. S. S., Sukhacheva, M. V., et al. (2015b). Methanosalsum natronophilum sp. nov., and Methanocalculus alkaliphilus sp. nov., haloalkaliphilic methanogens from hypersaline soda lakes. Int. J. Syst. Evol. Microbiol. 65, 3739-3745. doi: 10.1099/ijsem.0.000488

Sorokin, D. Y., Elcheninov, A. G., Toshchakov, S. V., Bale, N. J., Sinninghe Damsté, J. S., Khijniak, T. V., et al. (2019). Natrarchaeobius chitinivorans gen. nov., sp. nov., and Natrarchaeobius halalkaliphilus sp. nov., alkaliphilic, chitinutilizing haloarchaea from hypersaline alkaline lakes. Syst. Appl. Microbiol. doi: 10.1016/j.syapm.2019.01.001. [Epub ahead of print].

Sorokin, D. Y., Khijniak, T. V., Kostrikina, N. A., Elcheninov, A. G., Toshchakov, S. V., Bale, N. J., et al. (2018a). Natronobiforma cellulositropha gen. nov., sp. nov., a novel haloalkaliphilic member of the family Natrialbaceae (class Halobacteria) from hypersaline alkaline lakes. Syst. Appl. Microbiol. 41, 355-362. doi: 10.1016/j.syapm.2018.04.002

Sorokin, D. Y., Kublanov, I. V., Gavrilov, S. N., Rojo, D., Roman, P., Golyshin, P. N., et al. (2016a). Elemental sulfur and acetate can support life of a novel strictly anaerobic haloarchaeon. ISME J. 10, 240-252. doi: 10.1038/ismej.2015.79

Sorokin, D. Y., Kublanov, I. V., Yakimov, M. M., Rijpstra, W. I. C., and Sinninghe Damsté, J. S. (2016b). Halanaeroarchaeum sulfurireducens gen. nov., sp. nov., the first obligately anaerobic sulfur-respiring haloarchaeon, 
isolated from a hypersaline lake. Int. J. Syst. Evol. Microbiol. 66, 2377-2381. doi: 10.1099/ijsem.0.001041

Sorokin, D. Y., Makarova, K. S., Abbas, B., Ferrer, M., Golyshin, P. N., Galinski, E. A., et al. (2017a). Discovery of extremely halophilic, methyl-reducing euryarchaea provides insights into the evolutionary origin of methanogenesis. Nat. Microbiol. 2:17081. doi: 10.1038/nmicrobiol.2017.81

Sorokin, D. Y., Merkel, A. Y., Abbas, B., Makarova, K. S., Rijpstra, W. I. C., Koenen, M., et al. (2018b). Methanonatronarchaeum thermophilum gen. nov., sp. nov. and "Candidatus Methanohalarchaeum thermophilum", extremely halo(natrono)philic methyl-reducing methanogens from hypersaline lakes comprising a new euryarchaeal class Methanonatronarchaeia classis nov. Int. J. Syst. Evol. Microbiol. 68, 2199-2208. doi: 10.1099/ijsem.0.002810

Sorokin, D. Y., Messina, E., La Cono, V., Ferrer, M., Ciordia, S., Mena, M. C., et al. (2018c). Sulfur Respiration in a group of facultatively anaerobic natronoarchaea ubiquitous in hypersaline soda lakes. Front. Microbiol. 9:2359. doi: 10.3389/fmicb.2018.02359

Sorokin, D. Y., Messina, E., Smedile, F., Roman, P., Damsté, J. S. S., Ciordia, S., et al. (2017b). Discovery of anaerobic lithoheterotrophic haloarchaea, ubiquitous in hypersaline habitats. ISME J. 11, 1245-1260. doi: 10.1038/ismej.2016.203

Sorokin, D. Y., Toshchakov, S. V., Kolganova, T. V., and Kublanov, I. V. (2015c). Halo(natrono)archaea isolated from hypersaline lakes utilize cellulose and chitin as growth substrates. Front. Microbiol. 6:942. doi: $10.3389 /$ fmicb.2015.00942

Sprott, G. D., Agnew, B. J., and Patel, G. B. (1997). Structural features of ether lipids in the archaeobacterial thermophiles Pyrococcus furiosus, Methanopyrus kandleri, Methanothermus fervidus, and Sulfolobus acidocaldarius. Can. J. Microbiol. 43, 467-476. doi: 10.1139/m97-066

Sprott, G. D., Ekiel, I., and Dicaire, C. (1990). Novel, acid-labile, hydroxydiether lipid cores in methanogenic bacteria. J. Biol. Chem. 265, 13735-13740.

Sprott, G. D., Meloche, M., and Richards, J. C. (1991). Proportions of diether, macrocyclic diether, and tetraether lipids in Methanococcus jannaschii grown at different temperatures. J. Bacteriol. 173, 3907-3910.

Sturt, H. F., Summons, R. E., Smith, K., Elvert, M., and Hinrichs, K. U. (2004). Intact polar membrane lipids in prokaryotes and sediments deciphered by highperformance liquid chromatography/electrospray ionization multistage mass spectrometry - new biomarkers for biogeochemistry and microbial ecology. Rapid Commun. Mass Spectrom. 18, 617-628. doi: 10.1002/rcm.1378

Szekely, O., Steiner, A., Szekely, P., Amit, E., Asor, R., Tamburu, C., et al. (2011). The structure of ions and zwitterionic lipids regulates the charge of dipolar membranes. Langmuir 27, 7419-7438. doi: 10.1021/la200264s

Tachibana, A. (1994). A novel prenyltransferase, farnesylgeranyl diphosphate synthase, from the haloalkaliphilic archaeon, Natronobacterium pharaonis. FEBS Lett. 341, 291-294.

Tachibana, A., Yano, Y., Otani, S., Nomura, N., Sako, Y., and Taniguchi, M. (2000). Novel prenyltransferase gene encoding farnesylgeranyl diphosphate synthase from a hyperthermophilic archaeon, Aeropyrum pernix. Molecularevolution with alteration in product specificity. Eur. J. Biochem. 267, 321-328. doi: $10.1046 /$ j.1432-1327.2000.00967.x

Tamura, K., Stecher, G., Peterson, D., Filipski, A., and Kumar, S. (2013). MEGA6: molecular evolutionary genetics analysis version 6.0. Mol. Biol. Evol. 30, 2725-2729. doi: 10.1093/molbev/mst197

Teixidor, P., Grimait, J. O., Pueyo, J. J., and Rodriguez-Valera, F. (1993). Isopranylglycerol diethers in non-alkaline evaporitic environments. Geochim. Cosmochim. Acta 57, 4479-4489. doi: 10.1016/0016-7037(93)90497-K
Tenchov, B., Vescio, E. M., Sprott, G. D., Zeidel, M. L., and Mathai, J. C. (2006). Salt tolerance of archaeal extremely halophilic lipid membranes. J. Biol. Chem. 281, 10016-10023. doi: 10.1074/jbc.M600369200

Tindall, B. J., Ross, H. N. M., and Grant, W. D. (1984). Natronobacterium gen. nov. and Natronococcus gen. nov., two new genera of haloalkaliphilic archaebacteria. Syst. Appl. Microbiol. 5, 41-57. doi: 10.1016/S0723-2020(84)80050-8

Valentine, D. L. (2007). Adaptations to energy stress dictate the ecology and evolution of the Archaea. Nat. Rev. Microbiol. 5, 316-323. doi: 10.1038/nrmicro1619

Villanueva, L., Damsté, J. S. S., and Schouten, S. (2014). A re-evaluation of the archaeal membrane lipid biosynthetic pathway. Nat. Rev. Microbiol. 12, 438-448. doi: 10.1038/nrmicro3260

Wang, Q., Li, W., Yang, H., Liu, Y., Cao, H., Dornmayr-Pfaffenhuemer, M., et al. (2007). Halococcus qingdaonensis sp. nov., a halophilic archaeon isolated from a crude sea-salt sample. Int. J. Syst. Evol. Microbiol. 57, 600-604. doi: 10.1099/ijs.0.64673-0

Xu, X.-W., Wu, Y.-H., Wang, C.-S., Oren, A., Zhou, P.-J., and Wu, M. (2007). Haloferax larsenii sp. nov., an extremely halophilic archaeon from a solar saltern. Int. J. Syst. Evol. Microbiol. 57, 717-720. doi: 10.1099/ijs.0. 64573-0

Xu, Y., Wang, Z., Xue, Y., Zhou, P., Ma, Y., Ventosa, A., et al. (2001). Natrialba hulunbeirensis sp. nov. and Natrialba chahannaoensis sp. nov., novel haloalkaliphilic archaea from soda lakes in Inner Mongolia Autonomous Region, China. Int. J. Syst. Evol. Microbiol. 51, 1693-1698. doi: 10.1099/00207713-51-5-1693

Xu, Y., Zhou, P., and Tian, X. (1999). Characterization of two novel haloalkaliphilic archaea Natronorubrum bangense gen. nov., sp. nov. and Natronorubrum tibetense gen. nov., sp. nov. Int. J. Syst. Bacteriol. 49(Pt 1), 261-266. doi: 10.1099/00207713-49-1-261

Xue, Y., Fan, H., Ventosa, A., Grant, W. D., Jones, B. E., Cowan, D. A., et al. (2005). Halalkalicoccus tibetensis gen. nov., sp. nov., representing a novel genus of haloalkaliphilic archaea. Int. J. Syst. Evol. Microbiol. 55, 2501-2505. doi: 10.1099/ijs.0.63916-0

Yoshinaga, M. Y., Kellermann, M. Y., Rossel, P. E., Schubotz, F., Lipp, J. S., and Hinrichs, K.-U. (2011). Systematic fragmentation patterns of archaeal intact polar lipids by high-performance liquid chromatography/electrospray ionization ion-trap mass spectrometry. Rapid Commun. Mass Spectrom. 25, 3563-3574. doi: 10.1002/rcm.5251

Yoshinaga, M. Y., Wörmer, L., Elvert, M., and Hinrichs, K.-U. (2012). Novel cardiolipins from uncultured methane-metabolizing archaea. Archaea 2012:832097. doi: $10.1155 / 2012 / 832097$

Conflict of Interest Statement: The authors declare that the research was conducted in the absence of any commercial or financial relationships that could be construed as a potential conflict of interest.

Copyright (๔ 2019 Bale, Sorokin, Hopmans, Koenen, Rijpstra, Villanueva, Wienk and Sinninghe Damsté. This is an open-access article distributed under the terms of the Creative Commons Attribution License (CC BY). The use, distribution or reproduction in other forums is permitted, provided the original author(s) and the copyright owner(s) are credited and that the original publication in this journal is cited, in accordance with accepted academic practice. No use, distribution or reproduction is permitted which does not comply with these terms. 